edukafé

documentos de trabajo de la Escuela

Cali, Colombia

ISSN 2711-2799 (en línea)
ICESI

número 7

Agosto 2019

\title{
Sistematización de Prácticas educativas: Guía conceptual para educadores
}

Alice Castaño José Dario Saenz Carlos Andres Ávila Héctor Fabio Bianchá Jhonny Segura Antury Juan Carlos López-García

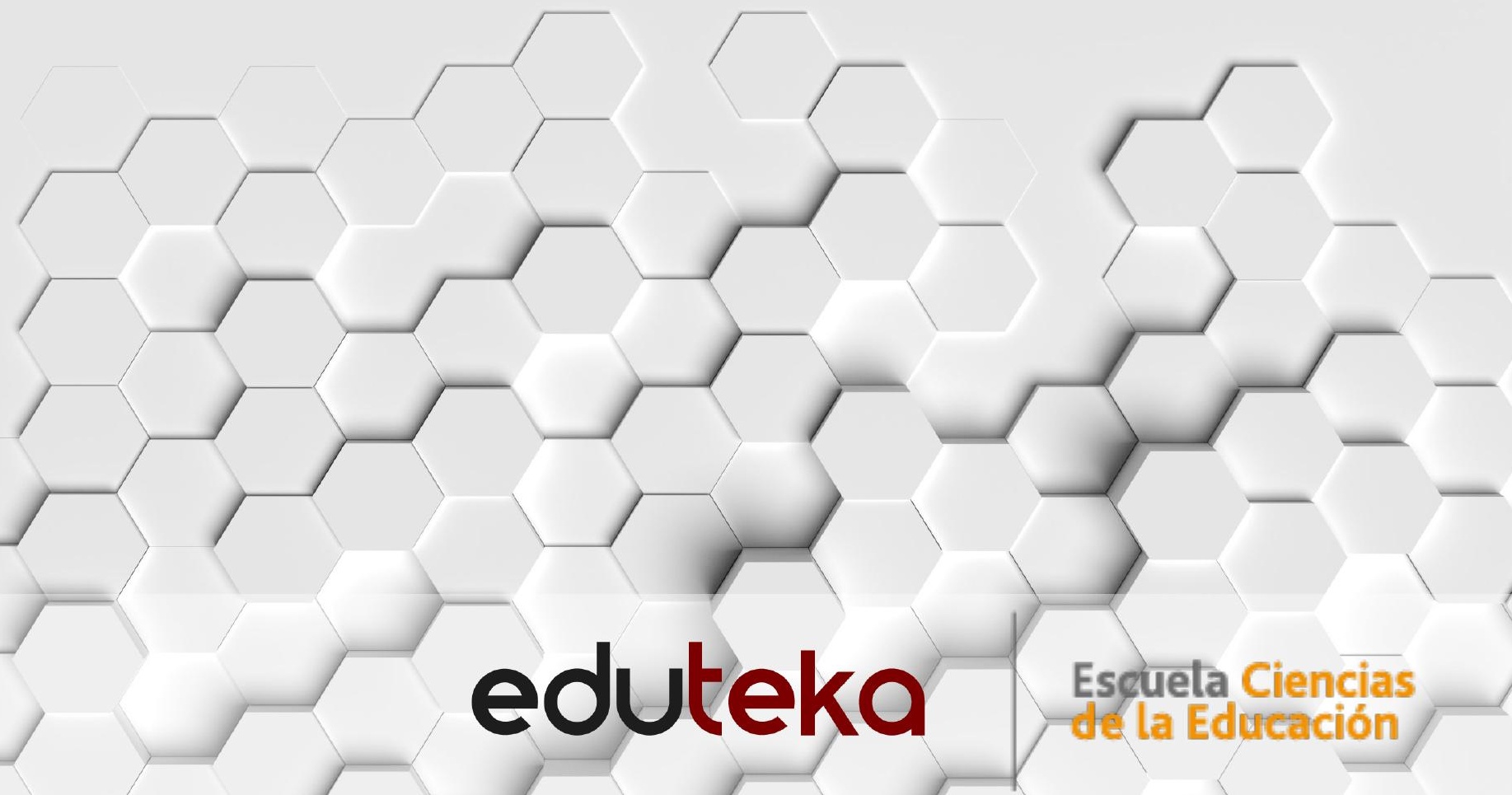


Número 7 • Agosto 2019

ISSN: 2711-2799 (en línea)

DOI: http://doi.org/10.18046/edukafe.2019.7

Rector: Francisco Piedrahita Plata

Secretaria general: María Cristina Navia Klemperer

Director académico: José Hernando Bahamón Lozano

Directora de la Escuela de Ciencias de la Educación: Ana Lucía Paz Rueda

Director del Centro Eduteka: Alejandro Dominguez Z.

Editor del portal Eduteka: Juan Carlos López-García • http://eduteka.icesi.edu.co

\section{Comité Editorial}

Ana Lucía Paz Rueda

Diana Margarita Díaz

Hoover Delgado Madroñero

Jhonny Segura

José Darío Saenz

Edición: Centro Eduteka

Editorial Universidad Icesi • Coordinación editorial: Adolfo A. Abadía

editorial@icesi.edu.co•https://www.icesi.edu.co/editorial

Diseño editorial y diseño portada: Juan Carlos López-García

Diseño del logo edukafé: Boris Sánchez Molano y Carlos Andrés Ávila

Imágenes de portada y contraportada: Magic Creative • Tokyo/Japan • pixabay.com

\section{Universidad Icesi}

Centro Eduteka

Escuela de Ciencias de la Educación (ECE)

Calle 18 No. 122-135 Pance • Cali - Colombia

Teléfono: +57 (2) 5552334 • Fax: +57 (2) 5551441

jclopez@icesi.edu.co•http://eduteka.icesi.edu.co/articulos/edukafe

\author{
Vladimir Rouvinski \\ José Benito Garzón M. (Unicatólica)
}

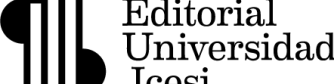
Icesi

Favor citar este documento de trabajo de la siguiente forma:

Saenz, José Dario; Segura Antury, Jhonny; López-García, Juan Carlos; Héctor Fabio, Bianchá; Ávila, Carlos Andres y Castaño, Alice (2019). Sistematización de Prácticas Educativas: Guía conceptual para educadores. Edukafé, Documentos de trabajo de la Escuela, No. 7. Cali: Universidad Icesi. Recuperado, el 25 de Agosto de 2019, de Eduteka: http://doi.org/10.18046/edukafe.2019.7

El Centro Eduteka no se hace responsable de las ideas expuestas, los modelos teóricos presentados o los nombres aludidos por el(los) autor(es) de los artículos publicados en la colección edukafé. El contenido de esta publicación es responsabilidad exclusiva del(los) autor (es), y no reflejan la opinión de las directivas de la Universidad Icesi, del Centro Eduteka, de la Escuela de Ciencias de la Educación (ECE), o de los editores de EDUKAFÉ - DOCUMENTOS DE TRABAJO DE LA ESCUELA

Licencia Creative Commons • Atribución/No-comercial/Compartir-igual

Esta licencia le permite distribuir, remezclar, retocar, y crear a partir de este este documento de modo no comercial, siempre y cuando se dé el crédito explícito a su(s) autor(xs) y a la Universidad Icesi y se licencien las nuevas creaciones bajo las mismas condiciones.

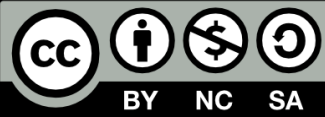




\section{Contenido}

1. Resumen

2. Introducción

3. Análisis sobre los elementos constitutivos de la sistematización de prácticas educativas.

4. Propuesta de fases de la sistematización de prácticas educativas.

5. Bibliografía.

6. Anexo 1: Algunas definiciones de sistematización de experiencias.

\section{edukafé}

"Frente a una taza con café se piensa, pero también se discute, se recuerda o se argumenta. Frente a la taza con café se columbra, se reflexiona, se sueña, se imagina, se escribe, se conversa... Y el café, el misterioso café escucha, profetiza, atestigua, aconseja, da fe, observa, asiente..."

Gustavo Máynez Tenorio

\section{http://eduteka.icesi.edu.co/articulos/edukafe}

Este documento de trabajo hace parte de la colección "edukafe" consistente en una serie de "working papers" escritos y publicados por profesores de la Escuela de Ciencias de la Educación de la Universidad Icesi con los que se busca apoyar la reflexión y la investigación en educación. Estos documentos pueden considerarse como "provisionales" yse publican bajo licencia Creative Commons (BY-NC-SA) para así estimular el debate académico entre diversos actores de la educación. Debate que puede tomar la forma de conversación, discusión, recuerdo, argumento, reflexión, sueño, escritura o conjetura; ojalá, frente a muchas tazas con café humeante.

Tal como lo plantea Marin-Garcia \& Garcia-Sabater (2010)*, los documentos de trabajo tienen como finalidad facilitar el acceso al debate académico de avances y resultados de trabajos de investigación, así como de fragmentos de investigación que posteriormente se pueden convertir en artículos científicos. De esta manera, estos trabajos académicos provisionales se vuelven citables y por tanto protegidos del plagio de ideas escritas y publicadas en versiones preliminares, sin menoscabo de ser divulgadas en los medios digitales o físicos que su autor considere adecuados.

* Marin-Garcia, Juan \& Garcia-Sabater, José (2010). Los Working Papers al senvicio de la escritura productiva. Working Papers on Operations Management. 1(1). doi:10.4995/wpom.v1i1.790 


\title{
Sistematización de Prácticas Educativas: Guía conceptual para educadores
}

\author{
Alice Castaño \\ José Dario Saenz \\ Carlos Andres Ávila \\ Héctor Fabio Bianchá \\ Jhonny Segura Antury \\ Juan Carlos López-García
}

\section{RESUMEN}

Este documento de trabajo introduce la fundamentación teórica de un modelo de sistematización de prácticas educativas (SPE) todavía en construcción- por parte de un grupo de profesores del Seminario de Sistematización adscrito a la Escuela de Ciencias de la Educación de la Universidad Icesi. Sin desconocer lo polisémico del término "sistematización", nuestro modelo concibe la sistematización como una perspectiva investigativa potente que, mediante un proceso reflexivo, permite que los distintos actores educativos construyan un relato colectivo sobre una práctica educativa en contexto, relato objeto de interpretación por parte de los mismo actores para generar nuevas perspectivas de conocimiento (microteoría confrontable con la teoría existente) que permita renovar y

Alice Castaño, Carlos Andres Ávila, Héctor Fabio Bianchá, Jhonny Segura Antury, José Dario Saenz y Juan Carlos López-García son profesores de la Escuela de Ciencias de la Educación de la Universidad Icesi, Cali, Colombia. Todos ellos pertenecen al grupo de investigación IRTA de la Universidad Icesi. 


\section{INTRODUCCIÓN}

Los avances de esta propuesta de sistematización de prácticas educativas son fruto del seminario de sistematización de la Escuela de Ciencias de la Educación (ECE) de la Universidad Icesi que funciona desde el segundo semestre de 2018, cuyo propósito es formular una ruta de investigación en educación. Esta propuesta, en construcción, es un documento útil para desarrollar sistematizaciones de prácticas educativas. La propuesta se espera desarrollar completamente como resultado de un proyecto de investigación aprobado por la oficina de investigaciones de la Universidad Icesi para ejecutarla en 2020.

Esta propuesta de sistematización de prácticas educativas se encuentra actualmente en construcción por un equipo de profesores de la ECE, por lo tanto, todos los documentos y recursos son para uso interno y exclusivo de profesores y tutores de proyectos de grado.

Esta primera entrega corresponde a la fundamentación teórica del modelo metodológico, el cual será presentado en un próximo documento de trabajo "Edukafé". En cuanto documento de trabajo, esperamos retroalimentación a partir de la implementación de la propuesta en los trabajos de grado a cargo de los docentes. El equipo de trabajo del seminario de sistematización está en disposición de apoyar puntualmente al profesor tutor en la implementación de la propuesta. 


\section{ANÁLISIS SOBRE LOS ELEMENTOS CONSTITUTIVOS DE LA SISTE- MATIZACIÓN DE PRÁCTICAS EDUCATIVAS.}

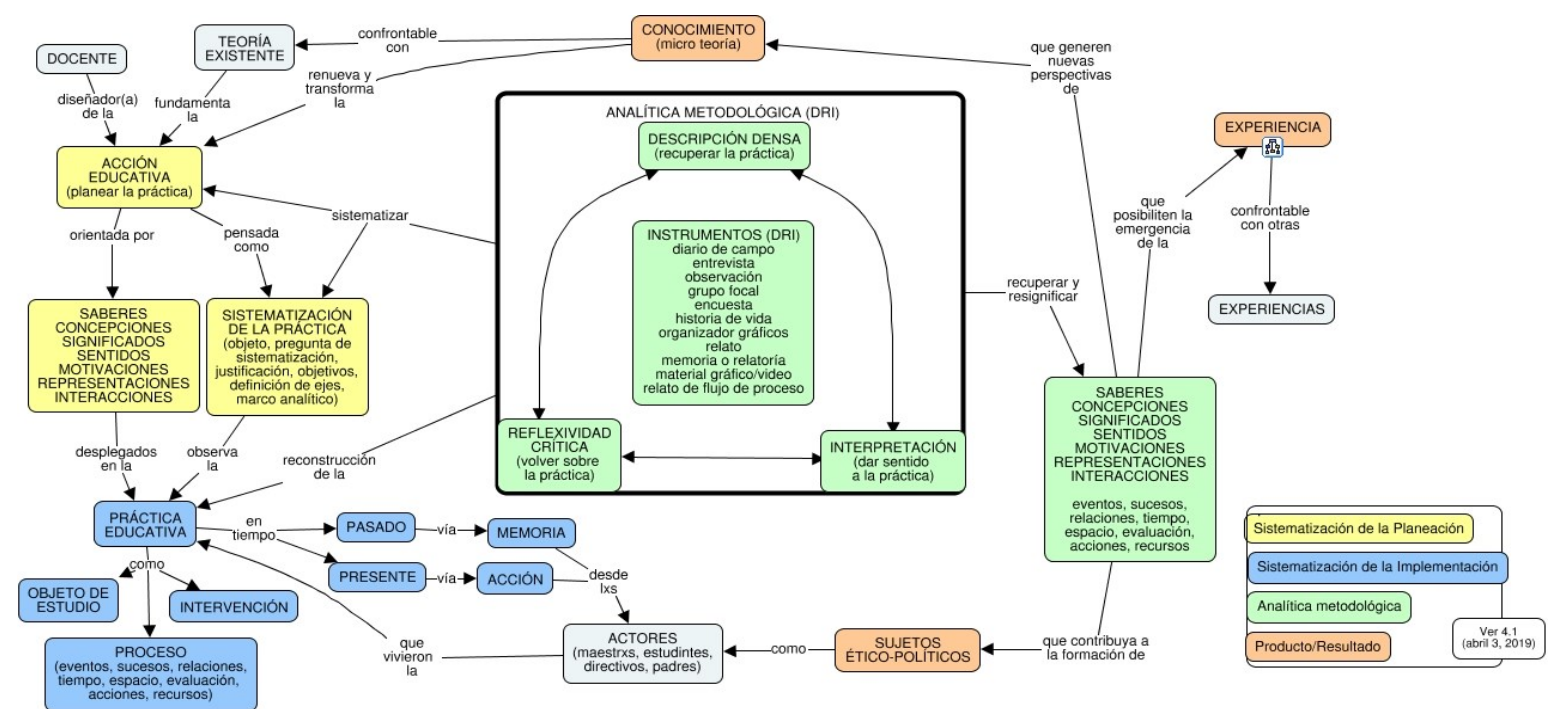

Gráfico 1. Propuesta analítica de sistematización de prácticas educativas

(Este gráfico analítico es fruto del seminario de sistematización de la Escuela de Ciencias de la Educación de la Universidad Icesi e intenta explicar el flujo del proceso de sistematización de experiencias educativas-En construcción).

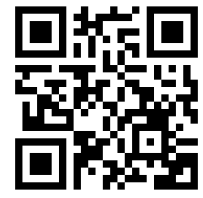

\section{1. ¿Qué entendemos por sistematización de una práctica educativa en pro- yectos de investigación/intervención en el aula?}

La sistematización de prácticas educativas, como estrategia metodológica, involucra cuatro dimensiones que la constituyen, y que deben tenerse en cuenta: práctica, teoría, epistemología y metodología, si aspira a generar nuevas perspectivas de conocimientos, vía micro teoría, en el ámbito de la educación. En principio, debe indicarse desde el inicio que, como en toda investigación, la pregunta, en este caso sobre la práctica educativa, se constituye en el eje en torno al que se produce la sistematización, es decir, es el punto de entrada para la sistematización. De igual manera, el proceso de sistematización tiene, para los propósitos de este documento, dos resultados finales: producir experiencia en los actores de la práctica y posibilitar el avance del conocimiento situado en el campo de la educación. Es por esto que tanto la formulación de la pregunta y la definición de los ejes específicos de la práctica, deben estar alineados con dicho propósito general. 
La sistematización como metodología permite una aproximación sistemática a las prácticas con el fin de comprender y conocer dimensiones específicas de la misma, siempre guiados desde posturas reflexivas e interpretativas. De tal manera, se puede afirmar que, en las dinámicas metodológicas de sistematización, son fundamentales tanto el proceso como el producto, pues ambos generan aprendizaje, saber, conocimiento y experiencia en quien o quienes la implementan.

Uno de los primeros interrogantes que es importante ir precisando tiene que ver con el origen del término sistematización: ¿por qué se le denomina sistematización? En principio se puede indicar que el término refiere a la ordenación académica de los procesos implicados en una práctica con el fin de darle sentido como unidad. De manera más específica, la sistematización procura develar, articulándolos, los elementos que constituyen la práctica como conjunto, con el fin darles orden y sentido para comprenderlos.

Veamos algunos elementos delineados por algunos autores sobre la sistematización y que son susceptibles de recuperar para este documento. La sistematización es considerada como una forma de interpretación crítica de una o varias experiencias que, a partir de su ordenamiento y reconstrucción, descubre o explicita la lógica del proceso, los factores que han intervenido en él, cómo se han relacionado entre sí y por qué lo han hecho de ese modo (Jara, 2015). Señala Jara (2015) que la sistematización produce un conocimiento crítico, dialógico y transformador, que puede ser muy útil para quiénes están implicados en dichas dinámicas sociales. Por su parte Barnechea y Tirado (2010), señalan que la sistematización es la reconstrucción y reflexión analítica de una experiencia mediante la cual se interpreta lo sucedido para comprenderla; por lo tanto, esta permite obtener conocimientos consistentes y sustentados, comunicarlos, confrontar la experiencia con otras y con el conocimiento teórico existente, y así contribuir a una acumulación de conocimientos generados desde y para la práctica. Expósito (2017) sugiere que sistematizar es detenerse, mirar hacia atrás, ver de dónde venimos, qué es lo que hemos hecho, qué errores hemos cometido, cómo los corregimos para orientar el rumbo, y luego generar nuevos conocimientos, producto de la crítica y la autocrítica, que es la dialéctica, para transformar la realidad. De tal manera que la sistematización, según los referidos autores, sugiere un ordenamiento reconstructivo de las prácticas con sentido reflexivo e interpretativo desde los actores de la práctica, así como la construcción de saber y conocimiento, y finalmente, la idea de desentrañar el sentido para la transformación.

De tal manera se puede señalar que el objeto de la sistematización educativa, en tanto diseño metodológico, son las prácticas educativas. Pero las prácticas, en tanto objeto de sistematización, requieren un ordenamiento con base en los fines de la investigación. La práctica es un objeto que se construye a partir de los fines y acciones desplegados por los actores educativos, bien de una práctica pasada o de una práctica que está en desarrollo. Así, la sistematización, en tanto proceso y producto, es una dinámica que activa, de forma metódica, la pla- 
neación, implementación, recolección de información descriptiva, la reflexividad crítica y la interpretación (DRI) sobre las prácticas. Si el objeto de la sistematización es la práctica, entonces, cómo conceptualizarlas para aprehenderlas y comprenderlas. Teniendo en cuenta que la práctica es el objeto de sistematización, se deben desarrollar estrategias metodológicas que permitan, a partir de ella, recuperar y resignificar nuevas experiencias y conocimientos desde los actores implicados. Reconociendo que este proceso se desarrolla desde el conjunto de concepciones, significados, sentidos, representaciones, acciones y saberes puestos en juego durante las relaciones e interacciones del proceso educativo denominado práctica educativa.

Dado que el término "sistematización" es polisémico, debemos dejar en claro cuál es la perspectiva y el significado de tal término en esta publicación; no sin antes indicar que otros sentidos del término pueden ser igualmente válidos, dependiendo del propósito que rija el proceso de sistematización (ver el anexo 1: Algunas definiciones de sistematización). En este documento entendemos la sistematización como un proceso tendiente a la generación de nuevas perspectivas de conocimiento confrontable con la teoría existente y que permita renovar y transformar la acción educativa de maestros y maestras. En tal sentido, la sistematización de prácticas educativas consiste en la reconstrucción ordenada de una práctica, vivida colectivamente en un contexto y proyecto particular, mediante un proceso reflexivo e interpretativo que implica volver la mirada de manera crítica hacia la forma en la que se vivió la práctica. En tal sentido, la sistematización busca construir una narrativa que posibilite la emergencia de la experiencia y la generación de nuevas perspectivas de conocimiento. Por tanto, a la experiencia se llega a partir de la práctica educativa.

\subsection{Sobre la práctica}

¿Qué entendemos por práctica en tanto objeto del proceso de sistematización? Es posible hablar de una teoría de las prácticas con diversos orígenes teóricos que no necesariamente tienen una unidad de significado, pero que indica que estamos frente a un asunto polisémico. Es posible tomar, en principio, los aportes de una perspectiva sociológica que pretende zanjar la discusión entre la acción y la estructura por vía de la teoría de las prácticas. Son Pierre Bourdieu y Anthony Giddens dos importantes representantes de dicha teoría. Para Bourdieu (1994), la práctica del agente se configura en la relación de la experiencia del sujeto con el sistema de posiciones y relaciones estructuradas en el que este se sitúa. El agente es producto de las condiciones de existencia y, en su trayectoria, es permeado por ellas, constituyéndose en él esquemas mentales que le habilitan para pensar, sentir, valorar y evaluar el mundo. Estos esquemas actúan y median en los momentos de toma de decisiones y acciones por parte del agente. En tal sentido, dar cuenta de las prácticas sociales impli- 
ca comprender la relación existente entre el habitus (esquemas internos del sujeto) y el campo, es decir, el conjunto de relaciones y posiciones estructuradas, en el marco del cual él se moviliza. La práctica siempre está contenida de la historia inscrita en el cuerpo del sujeto, el pasado se halla instalado en él y se activa en cada acción renovada en las maneras de pensar, sentir y obrar.

Por su parte, Giddens (1984) señala que la práctica tiene que ver con las actividades desplegadas por los sujetos en el tiempo y en el espacio. De igual manera, la práctica implica procesos hermenéuticos por parte del sujeto, así como acciones prácticas conducidas por el cuerpo sin que medien formas de reflexividad.

La recuperación de los elementos desplegados en la práctica, permite, mediante unos procesos de crítica de los conceptos, la autorreflexión y resignificación de la realidad sobre la que se despliega el acto educativo. Por ejemplo, hacerle preguntas a la realidad constituida, cuestionar lo estructurado, con el propósito de producir un texto que, en tanto objeto de análisis, descripción, reflexividad e interpretación (DRI), posibilite la emergencia, como experiencia enriquecida, de nuevas perspectivas de conocimiento relacionado con la realidad específica.

Las nuevas formas de conocimiento producidas proporcionan la renovación y transformación de las prácticas y los elementos asociados a ella. Es decir, el proceso de la sistematización produce aprendizajes capaces de retroalimentar las acciones iniciales que, enriquecidas en la sistematización, recreen nuevas formas de intervención.

Desde esta perspectiva, se precisa que la sistematización tiene como objeto de estudio a la práctica educativa, bien como sucesos pasados que se recuperan mediante la memoria de los actores implicados, pero también cómo momento de la acción presente que se recobra en el momento mismo del ejercicio de la práctica, como objeto etnográfico. De tal manera que la sistematización puede darse sobre la práctica desarrollada en tiempo pasado y, a su vez, sobre prácticas puestas en acción presente. En síntesis, se puede desarrollar procesos de sistematización sobre la acción y en la acción. Se utiliza, en principio, la diferencia entre práctica y acción, pues se considera que la práctica contiene no solo acciones sino procesos que ponen en relación la subjetividad y el contexto estructurado de relaciones sociales.

La noción de práctica puede tener una importante conexión con el concepto de acción social de Weber (2002), quien la define como acción orientada a otros con sentido. Con lo que se establece un vínculo entre el "movimiento" del cuerpo y las motivaciones subjetivas del sujeto. Así, en consideración del autor, hay un desplazamiento, como actividad, del sujeto hacia el otro, pero bajo la mediación de motivos y significados situados en el marco de la interacción social.

Se pueden identificar prácticas específicas del ámbito educativo, como aquellas que se des- 
tes en tanto sujetos de las prácticas con fundamento en saberes y conocimientos que orientan sus acciones; el tejido de relaciones e interacciones propiciadas por los actores centrales de la comunidad educativa; las interacciones políticas entre escuela y entorno educativo, etc. De tal manera que estos conjuntos de prácticas se constituyen en procesos que conectan una serie de eventos, propósitos, interacciones, sentidos, sucesos y recursos [Consideramos los recursos en cuanto, regularmente, hacen parte de todo ambiente de aprendizaje: contexto, saberes, interacciones, tiempo, espacio, medios y evaluación] más o menos "ordenados" y encadenados con miras a producir resultado educativo. Estas prácticas educativas se desarrollan en un tiempo y un espacio mediante interacciones entre disímiles actores individuales, colectivos e institucionales.

La práctica no es concebida como pura acción o actividad de los sujetos, pues como ya se indicó, se enmarca y despliega en sí misma, como un conjunto de condiciones objetivas y subjetivas. Como indica Jara, refiriéndose a la experiencia, esta se halla en "permanente movimiento" y abarcan, entre otras, las condiciones del contexto, las condiciones específicas de desarrollo de la práctica, las acciones, los aspectos subjetivos (percepciones, emociones, ideas, etc.), los efectos de la práctica, las relaciones e interacciones de los sujetos (2018 :153). En este mismo orden de ideas, Reckwitz indica que la práctica puede ser comprendida como actividades relacionadas con el cuerpo, la mente, las cosas y sus usos, estados de emocionalidad, es decir, forma un conjunto "cuya existencia depende necesariamente de la existencia y la interconexión específica de estos elementos, y que no puede reducirse a ninguno de estos elementos individuales (2002: 249-250).

\subsection{Analítica metodológica}

En esta propuesta, el proceso de sistematización parte de la práctica vivenciada colectivamente para, mediante un proceso que incluye descripción, reflexividad e interpretación (DRI), lograr que emerja la experiencia de manera que se posibilite la generación de nuevas perspectivas de conocimiento.

10

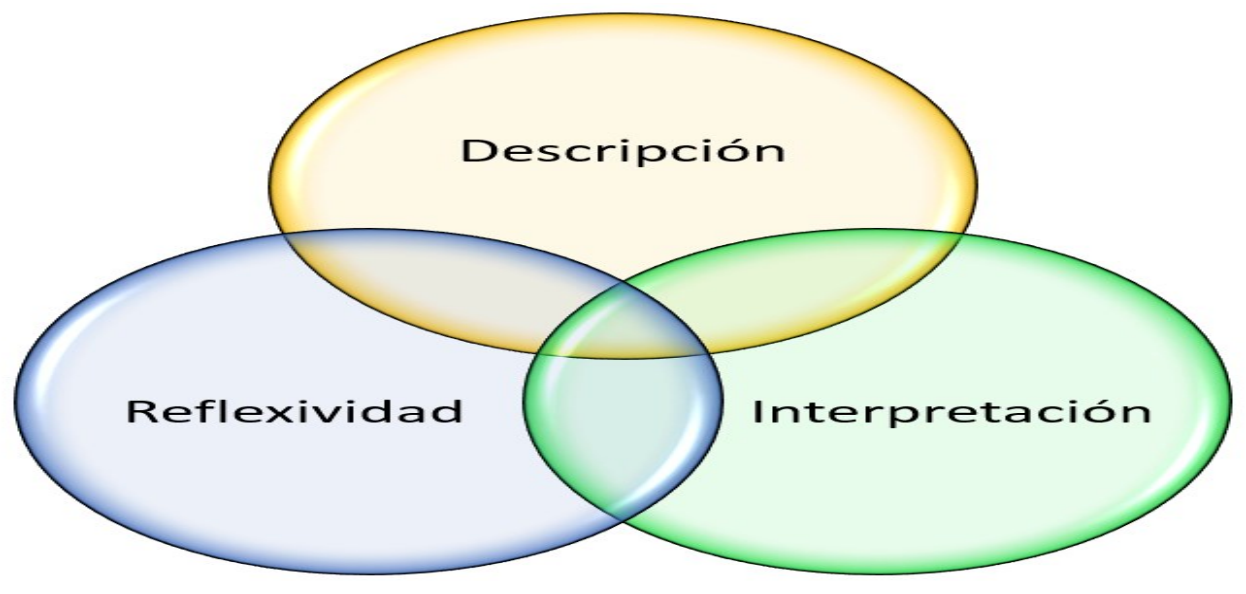


A continuación, se profundiza en cada uno de los elementos del DRI.

\subsubsection{Sobre las dinámicas de la descripción en la sistematización}

¿Qué es lo que se describe durante el proceso de sistematización? La descripción intenta dar cuenta, lo más rigurosamente posible, de los datos ("lo que se da") empíricos, los sucesos y los hechos observables inscritos en la práctica. Decimos empíricos en tanto nos referimos a datos que se suceden o tienen su origen en la práctica, en la experiencia y que son objeto de la observación de los hechos. De tal manera que se habla de conocimiento empírico cuando este refiere a las características de lo que "existe" y que se constituye en dato en tanto útil a los propósitos de la sistematización. Los datos, en tanto forma de representación simbólica, pueden ser cualitativos y cuantitativos. Están constituidos por informaciones, testimonios, documentos escritos (cartas, biografías, periódicos, documentos oficiales, fotografías,), sucesos, entidades, situaciones, cifras, textos, conversaciones, interacciones, relaciones.

El momento de la descripción es solo una fase del proceso de sistematización pues, como sabemos, los datos y los hechos por sí mismos no producen conocimiento, pero son la fuerza de la evidencia para crear nuevas imágenes que, acompañadas de la interpretación, permiten producir conocimiento. De igual manera, los datos deben ser puestos en contexto, puestos en relaciones y estructurados para poder "hacerlos hablar", hacerlos "decir cosas". La sistematización observa y describe acciones, relaciones e interacciones, objetos materiales, etc., pero también identifica lo que dicen los actores implicados en la práctica, los "interroga" y da cuenta de los documentos constituidos desde ellos, etc., todo con el fin de construir una representación que signifique la práctica. Es de tal manera que la sistematización construye, sobre la base de descripciones repletas de datos y mediadas por interpretación, conocimiento y experiencia. En tal sentido, es el proceso de interpretación, sustentado en evidencias, lo que posibilita avances en la construcción de conocimiento. Como se indica más adelante, descripción e interpretación son dos y un momento del trabajo de sistematización.

Recordemos que en el proceso de sistematización de prácticas educativas la descripción se constituye en una actividad cardinal para obtener información de todo lo que sucede durante la práctica. Es importante dejar en claro que la descripción nunca es total en tres sentidos: en primer lugar, debido a que en una práctica particular suelen ocurrir miles de hechos, pero sólo algunos son susceptibles de ser conquistados como datos, tal vez los que logramos capturar como significativos; en segundo lugar, porque nuestra "mirada" es limitada, nuestra capacidad de observación (el límite epistemológico del cuerpo) y de los instrumentos ordenados para "capturarlos" tienen siempre restricciones. Y, en tercer lugar, como indica Olivé "lo que cuenta como hecho y como objeto está condicionado a partir de cada concepción del mundo" (2004:185). Sabemos que toda descripción tiene una carga teórica de un lado, y de otro, tiene una fuerte carga de la concepción del mundo del observador, por lo que describir 
es de alguna manera interpretar. Refiriéndonos al trabajo del etnógrafo, puede señalarse que "la mirada que despliega [...], el lenguaje que usa, sus modos de registrar, lo que resalta en sus relatos, todo ello va moldeando su objeto de estudio" (Herrera, 2013:163).

La sistematización demanda describir acciones, relaciones, interacciones, espacios, tiempos, medios, contextos, actores en acción e interacción, expresiones e ideas, sentidos y significaciones de los actores, documentos y textos; en fin, todo aquello que, asociado a la práctica, se relaciona con el problema de sistematización formulado. La descripción debe insinuar movimiento y desplazamiento del fenómeno caracterizado, debe mediante su diseño establecer algunas de las formas que el fenómeno presenta, al menos, durante su observación. Pintar el desplazamiento del fenómeno insinúa la historicidad de la construcción del objeto social, de su estado cambiante y que sólo logramos capturar, mediante la descripción a manera de fotografía.

La descripción no es sólo la identificación y aprehensión del "dato crudo" según el problema planteado. Hay por lo menos dos asuntos relacionados con la descripción: uno, el proceso descriptivo siempre se debe desarrollar sobre la base del modelo analítico, marco teórico, conceptos o ideas teóricas que ha puesto al servicio de la comprensión de las prácticas el docente diseñador de la acción educativa. Dos, las nociones y categorías deberían guiar desde el inicio a la comprensión de la práctica objeto de sistematización o podrían ir emergiendo en los distintos momentos del proceso de sistematización, por ejemplo, durante la descripción. El punto es que entre la práctica como objeto de la sistematización y el proceso de pensamiento que implica la descripción, surgen ideas, conceptos y categorías que ayudan a constituir y moldear los datos aprehendidos, como indica Ragin (2007), se forman imágenes que son nutridas de elementos analíticos para darle un mayor sentido al dato. Hay una relación indisociable entre dato y concepto, entre lo simbólico y lo empírico durante el proceso de sistematización, podemos afirmar que, al describir, embadurnamos al dato de reflexiones e interpretaciones.

Son varios los asuntos procedimentales relacionados con la descripción. Por ejemplo: ¿De qué manera se obtienen los datos empíricos en el sentido de identificarlos y aprehenderlos? Los datos empíricos implicados en la práctica educativa objeto de la sistematización están constituidos por relaciones e interacciones sociales; pues cada acción, actividad, significación e idea pone en actividad relaciones; como diría Weber (1964), son acciones sociales con sentido y dirigidas a otros, quienes a su vez responden o reaccionan con sentido. Estos tejidos de relaciones, constituidos de prácticas y significaciones, deben ser recuperados de la manera más refinada posible por quien sistematiza y mediante los instrumentos puestos en juego.

12

¿Cómo se obtienen y producen las descripciones? Los datos pertinentes en una sistematización se obtienen a partir de los instrumentos diseñados para obtener, consignar y or- 
denar lo obtenido como descripción. Por supuesto que los instrumentos están relacionados con el diseño de la sistematización. Por ejemplo, un diseño de sistematización de prácticas educativas puede considerar el uso de instrumentos y técnicas tales como observación, entrevista, diario de campo, encuesta, grupos focales, historias de vida, organizadores gráficos, relatos, memorias o relatorías, materiales gráficos o de video, relatos de flujo de proceso, análisis de documentos, etc. Pero, ¿qué se produce a partir de la descripción? El resultado es un texto que contiene un relato colmado de datos e imágenes sobre las prácticas que se centran en el objeto específico formulado en el problema. El relato da cuenta de las especificidades del objeto, sus pautas, patrones, regularidades, variaciones, espacialidades, temporalidades, dimensiones, cantidades, texturas, etc. Pero los datos deben lograr un nivel de sentido que estructure un relato coherente con el problema y objetivo de la investigación. Quienes sistematizan deben cruzar información, establecer conexiones de datos, vincular sentidos y acciones de actores que están conectados con otros actores. En fin, le dan al relato un orden con significado, pues tienen la posibilidad de nombrar los procesos de la descripción. En últimas, la descripción clasifica, ordena, conecta, nombra, asocia, dimensiona, codifica, denomina, cataloga, numera, crea tipos, recupera y organiza mediante el lenguaje, una práctica.

¿Cómo se concilian descripción e interpretación, durante la sistematización? En general podríamos indicar que la descripción busca dar cuenta del objeto a través de la construcción de datos, intenta presentar un retrato lo más fielmente posible del objeto de estudio. Por su parte, la interpretación permite producir explicaciones y sentidos hermenéuticos desde quienes sistematizan; pues, sus imágenes y marcos analíticos tienen peso en la comprensión del objeto de estudio. El dato objetivo debe ser aprehendido por quienes sistematizan por medio de la subjetividad analítica como observación directa, con los instrumentos construidos desde su misma postura conceptual o con los construidos por otras personas con sus propios intereses.

Por último, una pregunta relacionada con lo que Ragin (2007:186) denomina "hacer progresar la teoría" mediante un enfoque de investigación comparativa en la que cada sistematización se constituya en un caso es la siguiente: ¿Qué papel juega el contexto específico en la práctica objeto de estudio? Dado que la sistematización, bajo la perspectiva propuesta por la Universidad Icesi, tiene como fin hacer emerger la experiencia y generar nuevas perspectivas de conocimiento, se deben considerar dos elementos: en primer lugar, considerar los datos contextuales si se quiere hacer progresar la teoría y en segundo lugar, realizar un análisis sistemático de similitudes y diferencias que permita explicar la diversidad entre varias sistematizaciones que comparten marcos analíticos o contextos similares.

La descripción, como el proceso de representación de la práctica como "realidad", es una actividad compleja en el desarrollo de una sistematización. Esta representación académica debe lograr construir imágenes lo más detalladas y precisas del objeto de descripción. Es posible desarrollar un buen trabajo descriptivo en la medida que se haya identificado, de 
forma anticipada, el objeto de la sistematización (la práctica), y como bien se sabe, este se constituye en el problema de sistematización con la formulación de la pregunta.

En términos epistemológicos se puede señalar, en primer lugar, que la descripción como proceso "objetivo", no se halla exenta y vaciada de perspectivas interpretativas. Es necesario admitir que el proceso descriptivo no está desembarazado de interpretación o de teoría como suponen quienes consideran que el momento de la descripción se reduce únicamente al momento empírico objetivo. Por otra parte, el tratamiento de una descripción juiciosa es el soporte de validez central a las interpretaciones e inferencias desarrolladas por quienes sistematizan. Un tratamiento diligente de la descripción se constituye en el terreno firme desde donde se erigen interpretaciones pertinentes y ajustadas sobre el objeto de sistematización.

El proceso descriptivo implica poner en juego tecnologías, dispositivos, metodologías, técnicas; así mismo, el cuerpo de quien describe con todos sus sentidos como vías por medio de los cuales aprehende el objeto en todas sus dimensiones. La descripción se apoya fundamentalmente tanto en el lenguaje humano como en otros tipos de formas de lenguaje que devienen de instrumentos metodológicos preparado para describir mediante gráficos, cuadros, imágenes, videos, etc. La descripción, implica, en principio, dar cuenta de las características centrales del objeto de estudio, con el fin de ofrecer una imagen que lo represente; de tal manera que implica observar y aguzar los sentidos, seleccionar y elegir, detallar y especificar, identificar los ritmos y las pausas, registrar las texturas y las tramas.

Es necesario indicar que el momento de la descripción siempre está acompañado de interpretación y, por supuesto, de imágenes capaces de producir conjeturas sobre los datos. La descripción no sólo va dando cuenta de los rasgos finos del fenómeno estudiado sino que va introduciendo categorías analíticas que aglomeran los datos y que, de igual manera, permite introducir comentarios preliminares interpretativos. La descripción es un paso en el proceso de sistematización, pues ella siempre debe estar acompañada tanto de nociones analíticas que amplíen su perspectiva explicativa como de formas de interpretación que identifique sentidos amplios, pues, la descripción por sí misma no desarrolla conocimiento en el sentido académico estricto. Según Geertz, la descripción etnográfica presenta cuatro rasgos característicos: es interpretativa, su interpretación es sobre el "flujo del discurso social", la interpretación rescata los discursos y los fija en "términos susceptibles de consulta” y, finalmente, es microscópica (2000:32). De esta idea del referido autor es importante destacar su íntima relación entre descripción e interpretación, por esta razón se plantea que el trabajo etnográfico produce, ante todo, descripciones densas.

Lo que en realidad encara el etnógrafo (salvo cuando está entregado a la más automática de las rutinas que es la recolección de datos) es una multiplicidad de estructuras conceptuales complejas, muchas de las cuales están superpuestas o enlazadas 
entre sí, estructuras que son al mismo tiempo extrañas, irregulares, no explícitas, y a las cuales el etnógrafo debe ingeniarse de alguna manera, para captarlas primero y para explicarlas después. Y esto ocurre hasta en los niveles de trabajo más vulgares y rutinarios de su actividad: entrevistar a informantes, observar ritos, elicitar términos de parentesco, establecer límites de propiedad, hacer censo de casas... escribir su diario (Geertz, 2000:24).

Así, según Restrepo (2018), la descripción implica interpretación y teoría, descripción de las acciones humanas, pero también de lo que piensa, más aún y precisando, de las relaciones entre las prácticas y los significados de éstas para los sujetos situados.

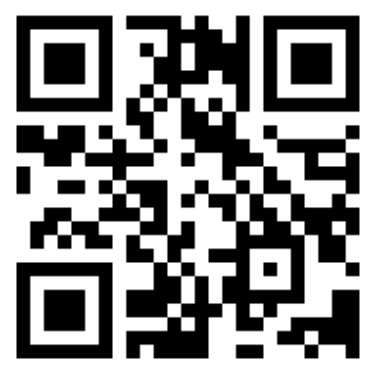

Sesión 1

https://bit.ly/2I19LKW

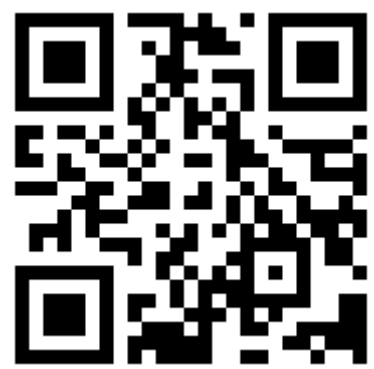

Sesión 2

https://bit.ly/2T1AvRB

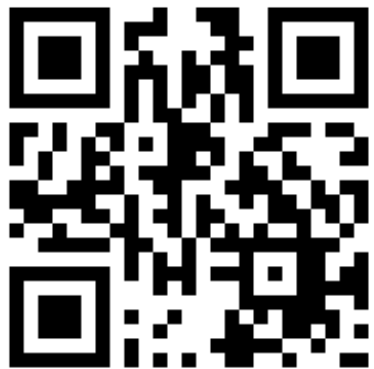

Sesión 3

https://bit.ly/3clu3N8

Restrepo, Eduardo (2018). Taller de etnografía. [archivo de Video]. Facultad de Ciencias Sociales UNMSM.

La recolección y tratamiento de los datos que se van describiendo es un proceso que implica ideas y conceptos que se van reformulando y rectificando desde el trabajo empírico. Como indica Ragin, "el uso de pruebas empíricas para formular o reformular las ideas generales se conoce como inducción”, pues ella permite evaluar las consecuencias de las pruebas empíricas para las ideas generales (1994: 46). Sin embargo, un proceso de razonamiento más apropiado para generar tanto nuevas ideas como hipótesis explicativas (conjeturas) de fenómenos o eventos es la abducción o retroducción. Una buena descripción debe contener todos los elementos para que el maestro que lidera el proceso de sistematización pueda llegar a explicaciones racionales.

\subsubsection{Sobre la Reflexividad}

¿Cómo comprendemos la reflexividad como componente central del proceso de sistematización de las prácticas? Si el objeto de la sistematización es la práctica, la forma de aproximarse a esta es a través de dos dinámicas analíticas, pero también procedimentales: la reflexividad y la interpretación. La reflexividad, en primer lugar, es una manera en que el maestro deja de ser un técnico de pedagogía para constituirse en sujeto analítico, investigador y productor de conocimiento, es decir, es el lugar que lo constituye en sujeto activo de las prácticas. En segundo lugar, la reflexividad implica, de parte del maestro, una postura 
crítica tendiente a desnaturalizar lo construido, es decir, alternar, cambiar y transformar lo "establecido". En tercer lugar, requiere poner en juego una conducta evaluativa de todos elementos constitutivos de la práctica, con el fin de producir información para tomar decisiones de mejoramiento. En cuarto lugar, la reflexividad invita al maestro a que su práctica esté analíticamente orientada o, mejor aún, que su experiencia permita la emergencia de teorías prácticas. Y, finalmente, la postura reflexiva demanda el doble movimiento de observador de su propia práctica, pero sin perder su conexión con el contexto de relaciones implicadas en ella. Así, la reflexividad conduce al maestro a pensar sobre su acción en situación y, desde ese lugar, desarrollar posturas críticas y constructivas.

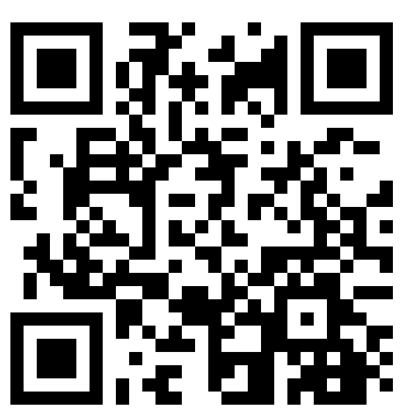

https://bit.ly/38lMu10

Herrera, José Dario (2019) ¿Qué es la sistematización de experiencias? [archivo de Video]

De otro lado, la reflexividad, en concepto de Dewey (2007: 90), implica el desarrollo de actitudes y conductas cuyo eje transversal es la lógica, en el sentido que inspecciona, ata cabos, reconoce, calcula, arriesga una explicación, detecta las relaciones entre los elementos. Por ejemplo, el sentido de la reflexividad convoca a estar alerta, ser "cuidadoso, riguroso definido y preciso", y ordenado, con miras precisas en el resultado y la conclusión. La actividad reflexiva, siguiendo al referido autor, indaga, estudia y revisa el material sobre el que descansa la conclusión. La reflexión regresa sobre la práctica del sujeto, le permite volver sobre sí mismo con propósitos de examinar exhaustivamente el curso de los eventos que constituyen su práctica, supone "una actitud exploratoria de indagación, cuestionamiento, crítica y búsqueda, sobre lo que se piensa", involucra el refinamiento del análisis con objeto de "argumentar, buscar explicaciones y relaciones" con lo cual emerge la dimensión metacognitiva del sujeto (Domingo y Gómez, 2014:44). El desarrollo o emergencia de la metacognición indica un proceso racional de conocimiento sobre el conocimiento que se produce, es desarrollar los niveles de consciencia sobre lo que se conoce.

En el proceso de sistematización el sujeto que constituye la práctica toma conciencia del hecho educativo en todas sus dimensiones, como momento en que se objetiva la acción. Este proceso implica tomar distancia, es decir, tratar de verla como algo externo; al separase de la práctica, y verla en todas sus dimensiones, se pasa a cuestionarla; es distanciamiento que 
posibilita la reflexión, en tanto proceso de autoconocimiento. En relación con los dos momentos posibles de la reflexión, sobre y en la acción, señala Perrenod que,

la reflexión en la acción provoca a menudo una reflexión sobre la acción, porque pone "en reserva" cuestiones imposibles de tratar en el momento, pero que el practicante quiere volver a analizar "con más calma"; no lo hace cada vez, pero sin embargo es uno de los recursos de la reflexión sobre la acción. La reflexión sobre la acción permite anticipar y preparar al practicante, a menudo sin él advertirlo para reflexionar más rápido en la acción y para prever mejor las hipótesis (2007:31)

La reflexión del sujeto que objetiva la práctica, requiere comprender qué es, para qué y cómo desencadenar su dinámica para constituirse en sujeto de educación. La reflexividad se dinamiza cuando el sujeto toma distancia de su accionar, y como acto intelectual de extrañamiento, el actor y su acción se constituyen en sujeto y objeto de conocimiento. Es la toma de distancia para aproximarse a la práctica como la objetivación que demanda la actitud etnográfica. La reflexión es deliberación interna con la intención de suscitar el alejamiento necesario para aproximarse con la mirada de asombro capaz de permitir que el ojo identifique las filigranas del detalle opacadas por el hábito habituado de la acción. El extrañamiento tiene que ver con el alejamiento que desnaturaliza lo familiar, lo normal, lo conocido, el sentido de lo común, que lo confronta con situaciones nuevas con el ánimo de comprenderlas.

Recordemos que el proceso de sistematización desarrolla procesos reflexivos centrados en la formulación del problema de sistematización. En tal sentido, el problema de sistematización identificado se constituye en el eje transversal del proceso y en torno al cual se articulan todas las dinámicas comprometidas en la sistematización. En tal caso la reflexividad esta enderezada a generar luces sobre el problema planteado. La reflexividad es autoconciencia de la práctica y el conocimiento que la instituyen por parte del sujeto en el marco institucional y de contexto general. La reflexividad es volver sobre sí mismo en estado de alerta sobre todos aquellos elementos que definen la práctica misma y sus efectos. De acuerdo con Giddens (1984), se puede la puede comprender como un rasgo del sujeto investigador cuando vuelve sobre su consciencia práctica (acciones que no son accesibles a una expresión discursiva explícita) con una consciencia discursiva (cuando el sujeto comprende lo que hace y da cuenta de las razones de su actuar). En el sentido del autor, estaríamos frente a una idea de reflexividad hermenéutica con la que el investigador debe contar al momento de explicar o comprender lo social de la práctica. Este momento de socioanálisis permite al investigador tomar conciencia del proceso de investigación así como de los sujetos que él involucra.

Señala Schön (1998) que la reflexividad se presenta durante el desarrollo mismo de la práctica, es decir, durante la acción, en el momento del ejercicio educativo. Sin embargo, se pueden desarrollar procesos reflexivos sobre prácticas pasadas, y, más aún, es posible adelantar procesos reflexivos para prácticas futuras sobre la base de las dos anteriores. Nos referimos 
a una reflexión en la acción práctica, que por supuesto difiere de la reflexión que se produce en el momento de formación del maestro en la universidad.

De otro lado, como indica Ramos, la reflexión en la práctica o práctica reflexiva, es un puente entre el individuo y su contexto que permite que los docentes "examinen críticamente sus actitudes, creencias, valores y prácticas de enseñanza que les permita identificar aquellas situaciones que requieren ser modificadas, reformuladas, mejoradas o innovadas (2013:1).

Hasta este momento se han explicita algunas ideas relacionadas con la reflexividad tal como ha sido pensada por algunos autores, pero se requiere, para ponerla al alcance de la sistematización como forma metódica, de ideas que permitan operacionalizar la noción de reflexividad. En este sentido se pueden proponer, desde varias perspectivas analíticas, algunas dimensiones que permitan aprehender operativamente la noción de reflexividad, tales como niveles de reflexividad, habilidades para generar reflexividad e instrumentos para motivar el ejercicio de la reflexividad.

Señala Mezirow (1998) que la reflexividad, como asunto complejo, tiene varios niveles que permiten su comprensión ejecutiva. En primer lugar, la reflexividad como volver sobre los propios conocimientos, asunto que puede ser entendido como autoconciencia de la propia práctica; dos, la reflexividad emocional; tres, la reflexividad como consideración de alternativas de acción; cuatro, la reflexividad como juicio crítico que examina los componentes y los distingue de la acción; cinco, la reflexividad en tanto comprensión de los conceptos; seis, la reflexividad de los aspectos psíquicos y, finalmente, la reflexividad comprensiva de los marcos teóricos (Citado en Domingo y Gómez, 2014). Esta comprensión de algunas dimensiones constitutivas del fenómeno reflexividad indica que este involucra diversos actos de pensamiento en el momento de la práctica.

Por su parte Atkins y Murphy (1993) sugieren cinco habilidades necesarias para iniciar un proceso reflexivo, que como disposiciones debe desarrollar quien se compromete con los procesos de sistematización. En primer lugar, autoconciencia como conciencia de sí mismo, como una manera de volver sobre sus propias acciones y pensamientos. En segundo lugar, la capacidad de descripción, que significa poder reconocer y organizar los hechos relevantes de la práctica, identificando sus características claves para expresarlas de forma comprensible. En tercer lugar, análisis crítico como el examen de los componentes de la situación con identificación del conocimiento relevante, las decisiones y las alternativas posibles. En cuarto lugar, síntesis, como la habilidad para integrar el nuevo conocimiento al conocimiento ya establecido. Finalmente, evaluación como el uso de criterios y estándares para determinar la validez de las acciones emprendidas. De igual manera se deben agregar otras disposiciones clave como la capacidad de identificar, establecer y organizar los hechos relacionados en la práctica. 
En relación con las formas operativas que activan la reflexividad en cada momento de la sistematización, se pueden proponer algunos dispositivos activadores. Domingo y Gómez (2014:122) proponen diez instrumentos “diseñados para incentivar la práctica reflexiva” y que pueden ser útiles para el trabajo metodológico considerado para la sistematización de prácticas educativas. En principio, sólo se nombran los dispositivos rastreados por los referidos autores: registro de aprendizaje reflexivo (RAR), mi estilo docente en construcción, habilidades y pauta para el estudio de un Caso, indagar sobre mi programación, explorar mi identidad docente, fortalezas y debilidades de un equipo docente, de la observación a la reflexión, fichas reflexivas, y pautas de evaluación reflexiva (PER).

\subsubsection{Sobre el proceso de interpretación}

La segunda dinámica del proceso de sistematización es la interpretación, que como ya se ha indicado, va de la mano con el proceso de descripción y de reflexión. Para Weber, quien toma distancia de posturas positivistas, la sociología es una "ciencia que pretende entender, interpretándola, la acción social para de esa manera explicarla causalmente en su desarrollo y efectos" (2002:5). En esta idea se concreta una conciliación entre interpretación y explicación, pues por la vía de la interpretación del sentido de la acción social se pueden hallar las regularidades que pueden ser las posibles causas que originan la acción social. De tal manera que, en consideración de Weber, es posible adelantar procesos de explicación a partir de la interpretación del sentido de la acción social, lo que nos conduce a comprender el objeto de investigación.

Si consideramos a la interpretación como un componente metodológico, diremos que este tiene como propósito descubrir-construir sentidos sobre las prácticas para poder dilucidarlas de manera coherente. Es el proceso mediante el que el dato empírico obtenido y construido con imágenes analíticas se mezcla de aspectos teóricos para hallarle significados que enhebren relaciones, interacciones, ideas, percepciones, etc., constituyentes de la práctica para construir su sentido y delinear explicaciones. El investigador debe plantearse preguntas que indaguen por el sentido más amplio y general de la acción desarrollada con el objeto de lograr captar regularidades, patrones, conexiones y vínculos de sentido entre los datos producidos en las descripciones.

En el marco de comprensión de este modelo la sistematización tiene un desplazamiento más allá de la simple reconstrucción de los "hechos" propiciados en la práctica, por tanto, se produce la reconstrucción descriptiva de la práctica desplegada, para, recuperándola, descifrar y hacer emerger nuevos sentidos, lecciones, conocimientos y saberes. En este proceso la interpretación cumple un papel central, en tanto combinación de datos empíricos, imágenes inductivas, comprensión analítica y orientación teórica. Es de esta manera que la sistematización involucra la interpretación como dimensión que no sólo se representa "realísticamente" la realidad construida durante la práctica, sino que reconstruye los proce- 
sos, es decir, los traduce a nuevas perspectivas, desentraña nuevas dimensiones de significado. En este proceso la pregunta es una buena puerta de entrada para lograr una adecuada explicación comprensiva del fenómeno pues implica el rescate del sentido de la práctica con el objeto de viabilizar nuevos significados sobre el hecho educativo con el fin de trazar renovadas formas de comprensión y acción. Habría que considerar que la reconstitución del sentido de la práctica no significa que este (el sentido) esté encriptado en la acción sino que este se construye en el proceso mismo de la práctica y de la investigación. Esta constitución del carácter del sentido de la práctica depende de las múltiples dimensiones con las que el maestro asiste al momento de la práctica; por ejemplo, sus dimensiones políticas, pedagógicas, contextuales, etc. Considerar la dimensión política en el sentido de la práctica, es lo que permitirá que el maestro se constituya como sujeto educativo.

La interpretación implica básicamente el momento en que los sujetos de la práctica constituyen el sentido de la práctica a partir de hacer que ella hable, es decir "darle una voz", no se sabe si nueva, pero eso sí, un sentido, un significado más amplio del que constituye la práctica misma. La interpretación se organiza sobre la fusión de tres momentos de análisis: la descripción de la práctica, la comprensión del sentido de la acción y el momento de reinterpretación enriquecida de la práctica.

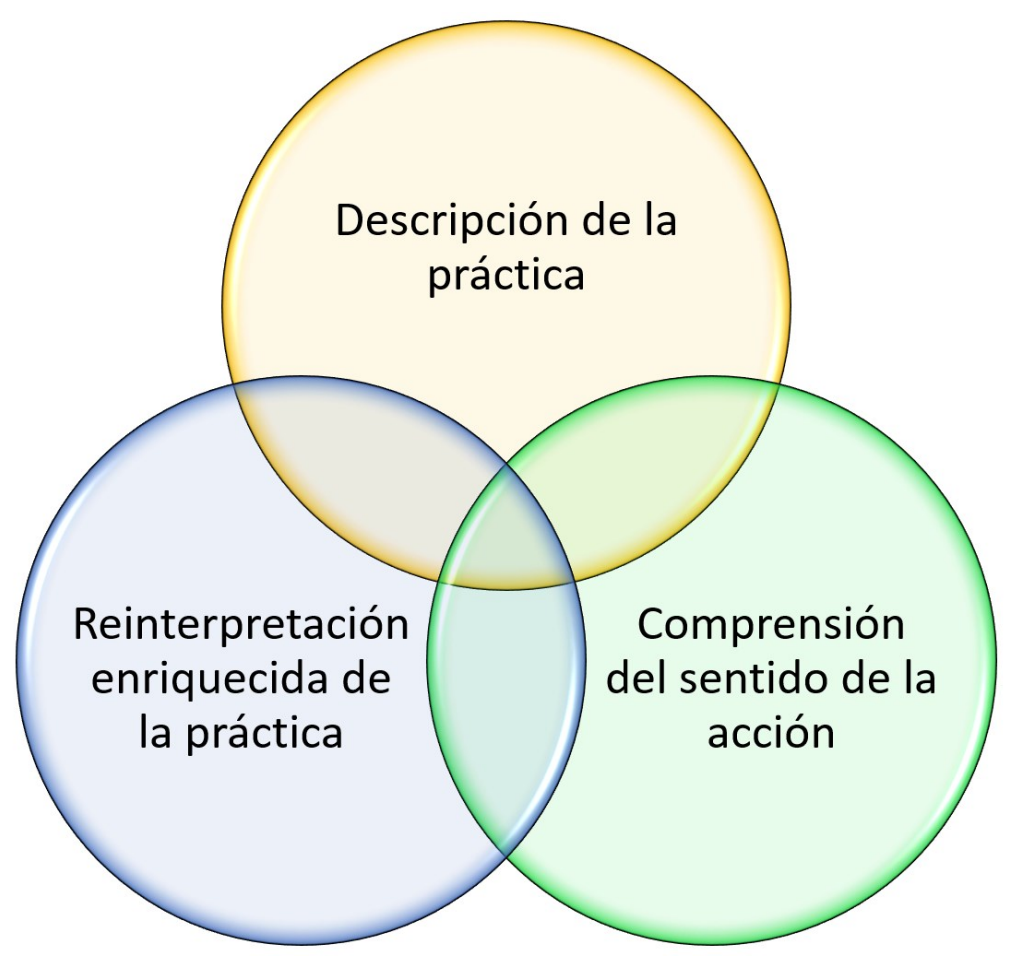

Tres momentos de análisis

La descripción da cuenta detallada de las características y los rasgos propios de la práctica desarrollada o que se desenvuelve. Es el momento de identificación de la realidad como construcción, pues más que identificar la realidad es hacer emerger la realidad. Recordemos 
que la descripción implica ideas y conceptos pues el proceso de descripción contiene teoría. Como producto de la descripción se obtiene un minucioso informe de los detalles que constituyen la práctica como sustrato de base para identificar nuevos fenómenos interpretativos. Por supuesto que la descripción está matizada por todas las consideraciones culturales, políticas y académicas del actor generador de la acción que, evidenciadas en el proceso, permite situarlas durante la sistematización. Toda descripción es una forma de selección de los aspectos considerados centrales o esenciales del objeto, lo que encarna finalmente es una forma de interpretación. Son muchos los elementos que median la descripción de las prácticas, pero es el problema y el marco analítico considerado en el proceso de sistematización el que tiene un peso significativo. La comprensión de la acción tiene como fin entender el sentido que engloba a la práctica, lo que se inicia con la puesta en relación de los datos obtenidos con los ya dispuestos en el sujeto de la práctica. Pues, como ya se ha indicado, la "captura" del sentido es una construcción a partir de lo que ya está elaborado en relación con las acciones objetivadas y la información de los significados ya elaborados en los sujetos. Interpretar y describir implican, a cada una, un requisito importante, por ejemplo, indica Sperber, "una interpretación es adecuada cuando es fiel, una descripción es adecuada cuando es verdad" (1991:124).

Esta dinámica permitirá a los sujetos de la práctica, la traducción y reconstrucción del hecho educativo constituido como nueva forma de expresión pues establece el vínculo entre el hecho de la práctica y sus propias elaboraciones y el contexto en el que él se sitúa. En el proceso de interpretación se involucran varios aspectos interesantes y necesarios. En primer lugar, el sujeto como descriptor e intérprete de la práctica, que es la suya, debe extrañarse a sí mismo estableciendo el lugar desde donde se sitúa para adelantar la práctica. En segundo lugar, puede adelantar perspectivas comparadas que le permitan hallar nuevos sentidos por contraste. En tercer lugar, no olvidar la pregunta y los elementos analíticos que permitan el ingreso a la comprensión de nuevos sentidos como la nuez constitutiva de diversos conocimientos y aprendizajes emergidos de la práctica. En cuarto lugar, la interpretación siempre es interrogativa, busca, mediante el cuestionamiento, hallar los significados de la práctica. Tal como indica Beuchot, "la pregunta interpretativa es siempre con vistas a la comprensión. ¿Qué significa este texto?, ¿qué quiere decir?, ¿a quién está dirigido?, ¿qué me dice a mí?, o ¿qué dice ahora?, y otras más" (2008:46). Son este tipo de interrogantes los que, trasladados al ámbito educativo, provocan la emergencia de significados amplios en el ámbito pedagógico. De tal manera que para poder interpretar y comprender la complejidad del objeto educativo "es necesario acceder al universo conceptual de los protagonistas educativos y a las redes de significado compartido al interior de las instituciones formadoras" (Mendoza, 2008:123). La interpretación en los procesos de sistematización obliga a una doble hermenéutica: una primera que involucra la reflexión comprensiva en el momento de la práctica y, un segundo momento, de interpretación sobre las primeras para hallar, como indica Mendoza, "inferencias con sentido". En quinto lugar, se recupera el sentido crítico de la sistematiza- 
ción como forma de distanciamiento reflexivo de la práctica para trasformar con sentido de reconstrucción de dicha realidad educativa. La reconstrucción se hace posible a partir de asociar y mediatizar las prácticas con nuevas perspectivas, ideas, conceptos, perspectivas analíticas, etc., Es de este proceso de mediación que puede emerger el nuevo conocimiento reconstruido, tal vez como microteoría, transformación de prácticas, saberes empíricos, etc., que en su conjunto constituyen aprendizaje experiencial (Domingo y Gómez, 2014:40), que redefinen el papel del maestro como sujeto educativo. Como indican Domingo y Gómez, para que el proceso de aprendizaje experiencial se produzca, se precisan tres elementos en interacción: la experiencia, la reflexión y el aprendizaje (2014:41).

Así, en la sistematización, la disposición para interpretar captando el significado de las acciones, y la reflexividad como una manera de volver racionalmente sobre la práctica desarrollada, se constituyen en dinámicas centrales para la configuración del sujeto educativo, es decir, del sujeto que crea y recrea realidades en los ámbitos de la profesión docente.

\subsection{Sobre la experiencia}

¿Cómo entender la experiencia en cuanto aprendizaje y saber adquiridos durante la sistematización de prácticas educativas? Con base en lo anteriormente expuesto es que se puede afirmar que la experiencia se constituye en un producto de la sistematización, es decir, no es el punto de partida del proceso (lo es la práctica) sino el punto de llegada. Es el momento en que el proceso de sistematización de la práctica (con todos los elementos que la constituyen) logra impactar el cuerpo y las subjetividades de los actores intervinientes. La experiencia surge de la práctica, pero como acción y como aprendizaje cualificado en la medida que, mediante la reflexividad y la interpretación, esta es superada y se constituye en nuevo conocimiento. Así, la práctica mediada por la reflexividad produce experiencia en la medida en que el sujeto maestro objetiva su práctica con pretensiones de aprendizaje (producir saber) e investigación (producir conocimiento).

Cuando se alude a la experiencia (adquirida, construida, lograda) que se constituye durante la sistematización de las prácticas, se hace referencia al conjunto de conocimientos prácticos, analíticos, organizacionales, de saber, etc., relacionados con el objeto específico de la práctica. La experiencia es una especie de conocimiento "global" de los múltiples aspectos singulares y específicos que se producen en el proceso relacionado con la práctica. Por ejemplo, una práctica vivida y observada se desarrolla como una ristra de sucesos interactivos y relacionales entre maestros, estudiantes, saberes pedagógicos, estrategias didácticas, saberes disciplinares y hechos institucionales, etc. La experiencia como resultado analítico de la puesta en escena de la práctica, en los términos de la sistematización, es siempre un proceso 
preparación que se ejercita, pero siempre mediada con momentos de reflexividad e interpretación con miras a producir nuevas formas de saber y conocimiento.

La experiencia se produce y desarrolla en el marco de las prácticas desplegadas con todo el cúmulo de asuntos que suceden en el momento de la práctica y el contexto que la comprende. El suceso o acontecimiento que interesa a la sistematización es la práctica en tanto dinámica colectiva con carácter educativo. Esta experiencia, de igual manera envuelve un entramado de relacionales, es decir, involucra la alteridad, el encuentro con otros, pues los procesos educativos se producen con la presencia activa, de al menos, maestros, estudiantes y la institucionalidad en la que se produce la experiencia. De otro lado, la experiencia, como proceso, ha permitido que el sujeto haya salido de sí mismo como dinámica de exteriorización de doble movimiento: que sale de los sujetos en relación con los otros, pero que regresa a los individuos. Sin embargo, ese movimiento de regresar sobre sí mismo implica un cambio como producto de la reflexividad.

De tal manera que la experiencia que emerge, como saber, conocimiento, información, constitución de sujeto y subjetividades, es el producto del suceso mismo como práctica, del tejido relacional que esta implica, junto con las dinámicas de reflexividad e interpretación tendidas en el proceso.

\subsection{Algunas consideraciones epistemológicas para la sistematización}

¿Qué fundamentos epistemológicos sustentan la sistematización de prácticas? Estos fundamentos de alguna manera legitiman la producción de conocimiento, y por supuesto, de saber y experiencia durante la sistematización como investigación educativa. La sistematización de prácticas educativas, tal como se concibe en este documento, tiene como objeto de investigación a las prácticas educativas, pero a partir de identificar problemas suscitados en ellas. Por tanto, la práctica, bien sea pasada o presente, se problematiza con el fin de identificar vacíos, cuestiones, dificultades y, desde allí, plantear y formular preguntas. La problematización requiere una actitud crítica sobre lo establecido, sobre aquello que se ha naturalizado; una gran capacidad de cuestionamiento de las prácticas, reflexividad sobre la acción, en fin, con conocimiento de causa lanzar preguntas sobre los asuntos relacionados con la práctica.

En relación con la dimensión epistemológica de la sistematización se deben indicar, sin ser exhaustivos, algunos presupuestos centrales relacionados con la producción de conocimiento y saber/experiencia logrados en la "intervención" como práctica. En primer lugar, el objeto de sistematización desde donde emergen formas de conocimiento y saber es la práctica educativa en la que está inmerso el maestro, pues recordemos que el maestro es sólo un actor de otros que están comprometidos en el proceso. Esta práctica tiene algunas característi- 
cas que tienen importantes implicaciones en la producción de conocimiento y experiencia. La práctica colectiva implica relaciones e interacciones entre actores educativos, y son ellos quienes constituyen el sujeto de la acción educativa. Como ya se ha indicado, para poder arrancarle conocimiento a la práctica, se deben adelantar dinámicas reflexivas y hermenéuticas, pues es desde este par de movimientos académicos que se hace posible que emerja nueva información que potencia el conocimiento del campo educativo.

En segundo lugar, en el momento de la sistematización el sujeto que sistematiza y el objeto de sistematización se confunden, se fusionan, no se constituye un distanciamiento capaz de escindir al sujeto que adelanta la práctica y el objeto, es decir la práctica. Esto se produce porque el conjunto de interacciones y relaciones que conectan la práctica con el entorno, el contexto institucional, el aula y los estudiantes, el proceso educativo, etc., se constituyen en el campo en el que se desarrolla la práctica, que, junto con el maestro, constituye el objeto de sistematización. Por ejemplo, el despliegue de una etnografía educativa como forma metodológica para identificar aspectos centrales de la práctica del maestro, se constituye en un trabajo de descripción analítica sobre el despliegue de acciones e interacciones educativas, es decir, autoetnografía. Pero como una manera de hacer emerger aspectos generales del campo educativo que se manifiestan en una práctica educativa particular. De tal manera que la superposición entre sujeto y objeto se presenta debido al poderoso vínculo dado entre la experiencia del sujeto maestro, con toda su carga subjetiva, y el desarrollo de la práctica educativa desplegada donde él es central. Así, en el caso de la autoetnografía, esta puede ser pensada como una "perspectiva epistemológica que sostiene que una vida individual puede dar cuenta de los contextos en los que le toca vivir a esa persona, así como de las épocas históricas que recorre a lo largo de su existencia" (Blanco, 2012:55). Pues, para el caso del presente documento, se supone que buena parte de los rasgos centrales de una sociedad particular (por ejemplo, una práctica educativa) puede ser descifrada a través de una buena descripción de la práctica y el sentido de un sujeto (una práctica educativa).

En tercer lugar, la práctica, como objeto de la sistematización, es una construcción colectiva que involucra a la institución educativa, maestros, estudiantes, etc. En tal sentido debe comprenderse como una construcción social. En cuarto lugar, los productos de la sistematización no tienen propósitos de generalización como conocimiento extensible a otras latitudes del campo específico de que se trate. Sus resultados, tanto los generados como conocimiento y como experiencia en quienes constituye el momento de la práctica es situado, no tiene más alcance que el referido a los actores de la práctica y al ámbito institucional. En quinto lugar, la práctica, objeto de estudio de la sistematización, no está exenta de las perspectivas, subjetividades y valoraciones propias de quienes participan de la práctica. En sexto lugar, la emergencia del conocimiento o saber, así como la experiencia que se logra en el proceso, se 24 sostienen fundamentalmente sobre procesos de orden inductivo. 


\subsection{El sujeto político en la sistematización de prácticas educativas}

¿De qué manera el proceso de sistematización de prácticas contribuye a la construcción de un sujeto político? En primer lugar, tratemos de comprender ¿qué entendemos por sujeto político? La política es el conjunto de acciones individuales y colectivas con el propósito de intervenir y constituir lo público, de darse un orden social deseado. Como fin, la política es la búsqueda y construcción colectiva de proyectos de sociedad, es decir, tiene como propósito la construcción del bien común. Como hecho social, la política se constituye en la acción de grupos de poder que, en conflicto y deliberación permanente, actúan públicamente. Así, la política como búsqueda del bien general y como acción pública de grupos de poder, son los elementos constitutivos y asociados a la construcción de orden social. La política es la salida colectiva de los grupos de poder para edificar lo social sobre la base de acuerdos colectivos con reglas de juego obligatorias a todos y garantizadas desde el poder político. De tal manera que la política como práctica es el lugar en que se constituye el sujeto que hace historia. No se refiere al ciudadano en tanto sujeto que funciona en el marco en relación con el Estado, sujeto de derechos y deberes que lo habilitan para constituirse en sujeto participante de la actividad política y del ordenamiento político.

De otro lado, retomamos de Touraine algunos desarrollos sobre la noción de sujeto que es supremamente útil para los fines analíticos del presente documento. En primer lugar, señala el autor que la constitución del sujeto se da en el marco de la reivindicación de la libertad, es decir, el sujeto es la afirmación de la libertad por lo que es imperativo "formar y fortalecer la libertad del Sujeto personal" (1996:278). En segundo lugar, relaciona la noción de sujeto con la de actor como "capacidad y voluntad de actuar", es decir, un sujeto que no sólo desarrolla y recrea pensamiento sino acción. Pero pensamiento y acción implica que el sujeto asume posturas críticas frente a las formas de dominación que le sujetan y disminuyen su autonomía, de tal suerte que, como indica Touraine, "toda apelación a una figura del Sujeto implica una crítica del orden" (1996:93).

Como se viene indicando, el sujeto político se involucra en entramados colectivos que aportan significativamente en su constitución como sujeto social. Así, inmerso en relación con otros, actúa sobre el mundo con el propósito de transformarlo. La incidencia en las realidades sociales significa, para Touraine, que la sociedad y los individuos son capaces de "actuar sobre sí mismos, ser actores de su propia historia y no únicamente consumidores, objetivos de publicidades, propagandas e influencias" (1996:148). Pues no se trata de un sujeto ensimismado y preocupado por su propio placer, al contrario, "remite al deseo, tanto colectivo como personal, de acción histórica y concentración de la experiencia vivida, desgarrada entre flujos económicos y raíces culturales" (1996:159). En fin, el sujeto es la posibilidad de reconocimiento del otro como "espacio de libertad pública" (1996:165). De otro lado, la construcción del sujeto demanda un lugar de acción e institucionalidad política de carácter 
democrático. Este marco contextual debe posibilitar a los "individuos, así como a los grupos, ser los actores de su propia historia en lugar de dejarse conducir ciegamente por la búsqueda de la ganancia, la creencia exclusiva en la racionalización, la voluntad de poder o la exaltación de valores comunitarios" (1996:270). Finalmente indica el autor que, "ese esfuerzo por ser un actor es lo que denomino Sujeto" (1996:21).

La idea de sujeto político, según Arias y Villota, instala al sujeto en el ámbito público como aquel lugar en el que la preocupación del sujeto es trascender del ámbito individual al colectivo y del ámbito privado al público. Es la condición en la que el individuo recupera la preeminencia de lo público sobre lo íntimo, de lo colectivo sobre lo individual, sin desconocer los espacios propios de la individualidad. De igual manera, el ámbito público demanda una actitud reflexiva sobre su condición de ser político en tanto sujeto constructor de su propia realidad. Así, reconoce la responsabilidad que tiene frente a la necesidad de incidir en la realidad mediante la acción organizada y reflexionada (Arias y Villota, 2007:41).

Según Niño, el maestro como sujeto político es aquel "capaz de protagonizar procesos significativos que posibiliten transformaciones" en el ámbito público, junto con los otros. De igual manera, indica una serie de cualidades que se potencian en la constitución del actor maestro, por ejemplo, la capacidad reflexiva sobre su acción, el cuestionamiento crítico de las realidades sociales, la toma de posición frente a las cosas y, ante todo, su disposición para incidir en la vida política. En consecuencia, el maestro como sujeto político es transformador, ya que en tanto sujeto de saber y poder que genera discursos y acciones, se constituye en protagonista de la vida pública con función política (Niño, 2013).

Plantea León (2013) que lo que inscribe al sujeto en el ámbito político es el hecho de "llevar a cabo acciones pensadas para transformar el entorno del cual forma parte", de igual manera, cuando el sujeto propende por la "construcción de propuestas pensadas para una realidad, con unos actores en particular, capaces de reflexionar su quehacer" en beneficio de la sociedad. En fin, la constitución de sujetos colectivos que actúan en pedagogía y en política.

En segundo lugar, ¿cómo se constituye el sujeto político? De un lado, la investigación puede constituirse en una importante actividad intelectual en la que el maestro puede constituirse como sujeto pedagógico y político. El maestro, desde su práctica y no sólo desde ella, es un productor de saber y conocimiento. De tal manera que la formación académica del maestro en el campo de la investigación le permite, en primer momento, formarse como un intelectual capaz de producir saber y conocimiento donde se funden investigación y acción. El movimiento pedagógico se constituye en ejemplo clave para comprender la manera en que la constitución de redes, el desarrollo de pensamiento pedagógico basado en la investigación y la acción política constituyen a sus integrantes no solo en actores pedagógicos sino en sujetos políticos con sentido de cambio. Plantea León que "la investigación se convierte en la práctica que permite posicionar el saber del docente y a éste como experto de la enseñan- 
za" (2013).

De otro lado, el sujeto maestro, tal como se ha venido sugiriendo en este documento, se constituye en actor a partir de las dinámicas colectivas que implican relación e interacción con otros. Esos otros son tal vez el grupo de pares con quienes comparte intereses y reflexiones académicas comunes a partir de lo cual constituye tejidos más amplios y potentes. Los otros son también las personas y grupos con quienes, y sobre quienes adelanta la investigación, etc. En este orden de ideas, y como indica Martínez (2006), las redes sociales en las que participan los maestros se constituyen en fuentes importantes para la constitución de sujetos políticos, así como potentes tejidos para la construcción de nuevas subjetividades. Las redes de maestros son espacios de reflexividad que sugieren, entre otras consideraciones, un pensamiento libre, sin ataduras, capaz de expresar sus argumentos sin cortapisas, sin temor. Por otra parte, es un pensamiento a contrapelo, desafiante, ante todo de las diversas formas de hegemonía establecida.

En síntesis, cuando pensamos en la construcción de maestros como sujetos políticos, cavilamos acerca de los elementos característicos que lo constituyen y que son efecto de su formación universitaria, de sus prácticas de ejercicio de la profesión docente y, por supuesto, de su experiencia académica y política con otros docentes dentro y fuera del lugar en que se ejerce como maestro. El punto central para este documento es la manera en que el proceso de sistematización de prácticas educativas aportan a la constitución de un sujeto político, no porque sea capaz de crearlo, sino porque puede potenciar las posibilidades de su acción. Este documento no pretende que en un proceso exclusivo de sistematización se desarrollen y potencien todas las posibilidades que implica constituirse en sujeto político, pero se indicarán algunas de sus posibilidades. En tal sentido, trataremos de mostrar algunos de los rasgos que pueden ser fortalecidos del sujeto político y, a su vez, un marco de referencia político importante para el proceso de sistematización de prácticas.

La sistematización es un proceso académico con implicaciones sociales, en tal sentido, requiere del maestro la voluntad para constituirse en un actor con capacidad de agencia para construir conocimiento, saber y experiencias alternativas desde la práctica como acción colectiva desde las redes de maestros, en los colectivos que se piensan una nueva escuela, etc. Un sujeto político en cuanto es capaz, con sus acciones investigativas, incidir en las realidades educativas y de quienes hacen parte de ellas: estudiantes, familias, los maestros, etc. es decir, se hace protagonista de la acción pública con capacidad y disposición de transformar los espacios públicos en los que actúa.

Un sujeto político que desarrolló su autonomía como capacidad de tomar sus propias decisiones en cuanto es capaz de pensar por sí mismo en los procesos de investigación e intervención de las realidades en las que se desempeña como profesional de la educación. Un sujeto político en cuanto reconoce en la investigación su capacidad para producir conocimien- 
to que lo constituye en un intelectual: sujeto de saber y de poder. Es una práctica potente para desarrollar la capacidad de pensamiento y habilidades de investigación en educación como forma de romper con la sola reproducción de conocimiento. La sistematización de prácticas transforma la experiencia educativa del maestro, así como sus perspectivas sobre su profesión, la escuela, los estudiantes, etc. Adquiere una comprensión y control sobre el mundo escolar, el momento histórico y su lugar en él. Un sujeto político con capacidad crítica y de cuestionar, de poner en discusión las significaciones y las reglas establecidas, con sentido crítico como manera de pensar a "contra pelo", como diría W. Benjamín. Con disposición de historizar, pues, como indica Villena, "conocer el pasado es una tarea ineludible del crítico social no sólo en tanto se aprende de él, sino principalmente porque es la única forma de desencadenar, actualizando, la energía mesiánica que está contenida en ese mismo pasado" (Villena, 2003:33). No sólo historizar sino constituirse en sujeto con conciencia histórica con capacidad para preguntarse por: ¿quién soy? ¿qué puedo hacer? ¿cómo tomar posiciones frente al momento en que actúo? Sujeto político reflexivo sobre sí mismo y sobre los otros y que, recupera la posibilidad de pensar futuros que riñen con los imperativos de la realidad, que se imagina futuros, que recupera la utopía. Un sujeto político con capacidad para reconocer el contexto histórico y la realidad social presente, es decir, un sujeto con capacidad analítica de reconocer el entorno político en el que se enmarca la realidad de la escuela y de la educación. Sujeto inmerso en la lucha política que participa y actúa por la construcción de un orden social deseado. Constituyente de nuevos ordenamientos. Sujeto con voluntad de acción para construir proyectos alternativos.

\subsection{La dimensión ético-política del sujeto}

¿Qué reflexiones éticas se ponen en juego durante el proceso de sistematización de prácticas educativas? La ética podemos entenderla como la reflexión razonada y analítica sobre el conjunto de valores que deben orientar la práctica de investigación en un contexto democrático. Tiene que ver con el análisis razonado, argumentado y crítico, sobre las decisiones de valor implicadas en el proceso de sistematización como práctica investigativa. Es el momento en que tomamos en serio y pensamos reflexivamente las consideraciones que regulan los procesos de la investigación.

Son muchas las consideraciones éticas que deben guiar la conducta del maestro en el proceso de investigación pues este proceso no es una práctica de pura habilidad técnica. De igual manera, la investigación no involucra sólo aspectos cognitivos en términos de la aprehensión de un objeto que orientado desde una teoría y de habilidades metodológicas y analíticas, produce conocimiento y experiencia. La sistematización de prácticas educativas tiene como objeto a las prácticas y esta está constituida por un conjunto de relaciones e interacciones entre seres humanos y, entre ellos y las formas institucionales y organizativas asocia- 
das a la escuela y su entorno, etc. Así, al trabajar con seres humanos, la sistematización educativa se impone consideraciones éticas en todas las fases que implica la producción de conocimiento, saber y experiencia. En tal sentido, la investigación nos impone adelantar reflexiones éticas sobre la mejor manera de proceder en las diferentes etapas del proceso de investigación, por ejemplo: durante el diseño de la investigación, durante el proceso de investigación, en relación con el o los sujetos con que se investiga, sobre los sujetos de investigación, sobre los resultados de la investigación, con la información obtenida, etc. El proceso también demanda sentido de responsabilidad con las consecuencias de la investigación, del respeto a la autonomía de las personas sujetos de investigación, etc.

\section{a. Consideraciones éticas durante el diseño y los objetivos de la investigación}

En la realización del proyecto de investigación es siempre importante, en el momento de la justificación de la investigación, preguntarse por las consecuencias y los beneficios de los resultados del trabajo.

\section{b. Decisiones éticas en el proceso de investigación}

En relación con los intereses y propósitos de la investigación en relación con las implicaciones, efectos y consecuencias sobre la vida social.

\section{c. Compromisos éticos entre los sujetos que investigan, personales e institucionales.}

De qué manera se comparte la información producto de la investigación con las personas sujeto de la investigación, así como con los colaboradores para que la investigación se produjera.

\section{d. Compromiso y responsabilidad ética para con los sujetos de investigación}

La relación que se establece con la población sobre la que se realiza la investigación. El consentimiento informado con las personas que nos ofrecen datos. Los debidos acuerdos sobre privacidad y confidencialidad de cierta información que pueda poner en riesgo a las personas, así como la comunidad.

El tipo de relación que se constituye con los "informantes", con aquellas personas que brindan información necesaria a la investigación. Relaciones que implican el respeto por su autonomía, intimidad, etc., pues sabemos que en general no se establece una relación simétrica entre investigador y población. Esto nos plantea el imperativo según el cual la población no es un medio de la investigación sino un fin.

\section{e. Responsabilidad ética con los resultados de la investigación}

Los resultados de la investigación; la calidad de la investigación, la veracidad de la información y resultados, la validez científica de los resultados, la presencia de plagio. 


\begin{tabular}{|c|c|c|}
\hline \multicolumn{3}{|c|}{$\begin{array}{l}\text { 4. PROPUESTA DE FASES DE LA SISTEMATIZACIÓN DE PRÁCTICAS } \\
\text { EDUCATIVAS (SPE) } \\
\text { La primera fase de la sistematización versa sobre la identificación y delimitación de la prác- } \\
\text { tica educativa objeto de la sistematización. En la segunda fase se diseña el proyecto de siste- } \\
\text { matización a partir de la práctica identificada en la fase anterior. En la tercera fase, se re- } \\
\text { construye y ordena la práctica mediante un proceso descriptivo, reflexivo e interpretativo. }\end{array}$} \\
\hline Fase 1 & Fase 2 & Fase 3 \\
\hline $\begin{array}{l}\text { Alistamiento del proceso de } \\
\text { sistematización }\end{array}$ & $\begin{array}{l}\text { Diseño del proyecto de S.P.E desde la } \\
\text { identificación de la práctica. }\end{array}$ & $\begin{array}{l}\text { Recuperación y reconstrucción de la práctica. } \\
\text { Meta-relato narrativo }\end{array}$ \\
\hline $\begin{array}{l}\text { Identificación, precisión y } \\
\text { contextualización histórico- } \\
\text { situada de la práctica } \\
\text { educativa objeto de la SEE y } \\
\text { sus actores. } \\
\text { Justificación. ¿Por qué y para } \\
\text { qué sistematizar está } \\
\text { práctica? ¿De qué manera } \\
\text { piensa transformar su propia } \\
\text { práctica? }\end{array}$ & $\begin{array}{l}\text { - Problema y pregunta de la } \\
\text { - Objematización. } \\
\text { - Definición de los ejes (y sub-ejes) de } \\
\text { la sistematización. } \\
\text { - Marco analítico (No necesariamente } \\
\text { se define de antemano, sino que } \\
\text { puede emerger en el proceso). } \\
\text { - Revisión de otras experiencias: } \\
\text { revisión de la literatura. } \\
\text { - Diseño metodológico de la } \\
\text { sistematización. } \\
\text { - Reflexión sobre la formulación del } \\
\text { proyecto de sistematización (este } \\
\text { elemento es transversal en esta fase } \\
\text { y en la construcción del documento } \\
\text { escrito). }\end{array}$ & $\begin{array}{l}\text { 1. Recuperar implica: } \\
\text { 2. Reconstruir } \\
\text { - Ordenar y clasificar el proceso de } \\
\text { planeación de la práctica con base en los } \\
\text { ejes mediante el DRI. } \\
\text { 3. Ordenar las acciones realizadas en el } \\
\text { diseño de la práctica. } \\
\text { 4. Identificar las fortalezas y debilidades } \\
\text { en el diseño de la práctica. } \\
\text { 5. Establecer los actores y sus roles clave } \\
\text { en el diseño de la práctica. } \\
\text { Ordenar y clasificar los momentos de la } \\
\text { implementación de la práctica con base en } \\
\text { los ejes mediante el DRI. } \\
\text { 1. Recuperar implica: } \\
\text { 2. Reconstruir } \\
\text { Ordenar los momentos de la } \\
\text { implementación de la práctica con base en } \\
\text { los ejes. } \\
\text { 3. Establecer el papel de los actores y sus } \\
\text { acciones con base en los ejes. } \\
\text { 4. Identificar los desafíos y oportunidades } \\
\text { con base en los ejes. } \\
\text { Indagar sobre las valoraciones de los }\end{array}$ \\
\hline
\end{tabular}


En la cuarta fase, se analiza la práctica como producto de un proceso descriptivo, reflexivo e interpretativo por parte de los actores. En la quinta fase, se destaca la experiencia educativa desde una perspectiva conceptual, identificando los nuevos conocimientos, transformaciones, aprendizajes y experiencia ganada. En esta fase, a partir de la interpretación de la práctica, emergen nuevos aportes a la disciplina (micro teoría), a la práctica y a la construcción del sujeto político y ético. En la sexta fase, se comunica la experiencia teniendo en cuenta el público al cual va dirigida y el soporte y formato en el que se presentará lo hallado.

\begin{tabular}{|c|c|c|}
\hline Fase 4 & Fase 5 & Fase 6 \\
\hline $\begin{array}{l}\text { El análisis, interpretación y reflexión del } \\
\text { relato producto de la recuperación y } \\
\underline{\text { reconstrucción de la práctica. }}\end{array}$ & Aprendizajes y experiencia & Comunicación de la experiencia \\
\hline $\begin{array}{l}\text { 1. } \quad \text { El análisis del relato } \\
\text { - } \text { Identificación de ejes y sub-ejes en el } \\
\text { - } \quad \text { Construcción del árbol analítico. } \\
\text { - } \quad \text { Reordenamiento del relato con base en } \\
\text { el árbol analítico. } \\
\text { 2. } \quad \text { La interpretación del relato reordenado } \\
\text { en la fase de análisis. } \\
\text { - Interrogar la práctica con el fin de } \\
\text { contrastar y relacionar (con otras } \\
\text { prácticas de colegas, teorías, prácticas } \\
\text { propias e investigaciones relacionadas } \\
\text { con su objeto- para hallar nuevos } \\
\text { sentidos para avanzar el conocimiento. } \\
\text { 3. La reflexividad sobre la práctica } \\
\text { interpretada. } \\
\text { - Identificar experiencias y saberes que } \\
\text { transforman la práctica. } \\
\text { - Recuperar el sentido crítico de la } \\
\text { sistematización como distanciamiento } \\
\text { reflexivo de la práctica. (Sujeto ético- } \\
\text { político). }\end{array}$ & $\begin{array}{l}\text { - Producción de experiencia } \\
\text { educativa/saberes como producto } \\
\text { del proceso de reflexividad } \\
\text { (orientado a mejorar las prácticas } \\
\text { educativas) } \\
\text { - Experiencia y aprendizajes del } \\
\text { maestro como sujeto ético y } \\
\text { político. }\end{array}$ & $\begin{array}{l}\text { - ¿Cuál es el propósito } \\
\text { comunicativo de la } \\
\text { sistematización? } \\
\text { - ¿A quién va dirigida? }\end{array}$ \\
\hline
\end{tabular}




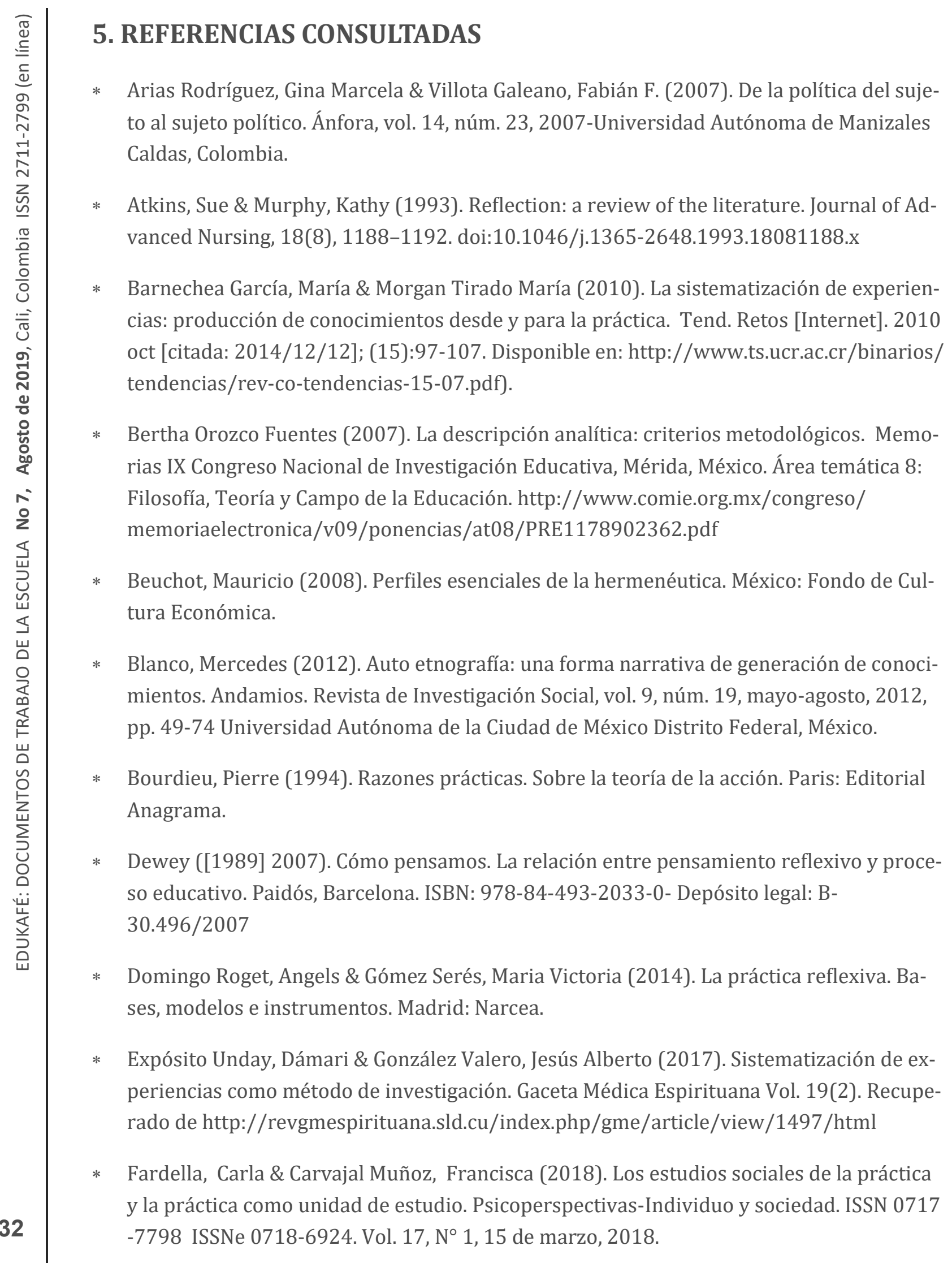


* Fierro, C.; Fortoul, B \& Rosas, L. (1999). Transformando la Práctica Docente. Una Propuesta Basada en la Investigación Acción. México: Paidós.

* Geertz, Clifford ([1973] 2000). La interpretación de las culturas. Gedisa editorial S.A, Barcelona.

* Giddens, Anthony (1984). La constitución de la sociedad. Bases para la teoría de la estructuración. Buenos Aires: Amorrortu Editores.

* Girola, Lidia (2011). Historicidad y temporalidad de los conceptos sociológicos. Sociológica (México). Vol.26 No. 73 México mayo/agosto Sociológica (México)versión On-line ISSN 2007-8358versión impresa ISSN 0187-0173

* Herrera, José Darío (2013). Pensar la educación, hacer investigación. Universidad De La Salle, Facultad de Ciencias de la Educación, Bogotá, D.C. Colombia.

* Herrera, José Dario (2 de Abril de 2019). ¿Qué es la sistematización de experiencias? [archivo de Video]. Recuperado del canal de Youtube de Carlos Eduardo Román Maldonado: https://www.youtube.com/watch?v=8oyupzIh6nA

* Jara, Oscar. (2015). La sistematización de experiencias produce un conocimiento crítico, dialógico y transformador. Docencia [Internet] 2015 May [citada 2014/12/12];(55):339. Disponible en: http://www.cepalforja.org/sistem/bvirtual/wp-content/ uploads/2015/06/Entrevista-Oscar-Jara-Revista-Docencia.pdf).

* Jara, Oscar (2018). La sistematización de experiencias: práctica y teoría para otros mundos posibles. CINDE

* León, Ana María (2013). El maestro como sujeto político: dilemas entre los imaginarios y su formación. Revista Infancias Imágenes / pp. 117 - 123 / Vol. 12. No. 1 / Enero - junio de 2013. Textos y contextos. file:///D:/Usuarios/16627712/Downloads/DialnetElMaestroComoSujetoPolitico-4817231\%20(10).pdf

* Martinez, María Cristina (2006). La figura del maestro como sujeto político: el lugar de los colectivos y redes pedagógicas en su agenciamiento. Educere, vol. 10, núm. 33, abriljunio, 2006, pp. 243-250 Universidad de los Andes Mérida, Venezuela. Educere La Revista Venezolana de Educación. https://www.redalyc.org/pdf/356/35603305.pdf

* Mejía, Marco Raúl (2008). La sistematización. Empodera y produce saber y conocimiento. Bogotá: Ediciones desde Abajo.

* Mendoza, Carmen Cecilia (2008). La hermenéutica: posibilidad en la búsqueda dl sentido de la práxis pedagógica. UPEL-Instituto Pedagógico Rural Gervasio Rubio. Sapiens: Revista Universitaria de investigación, año 9, No. 2, diciembre, 2008. 


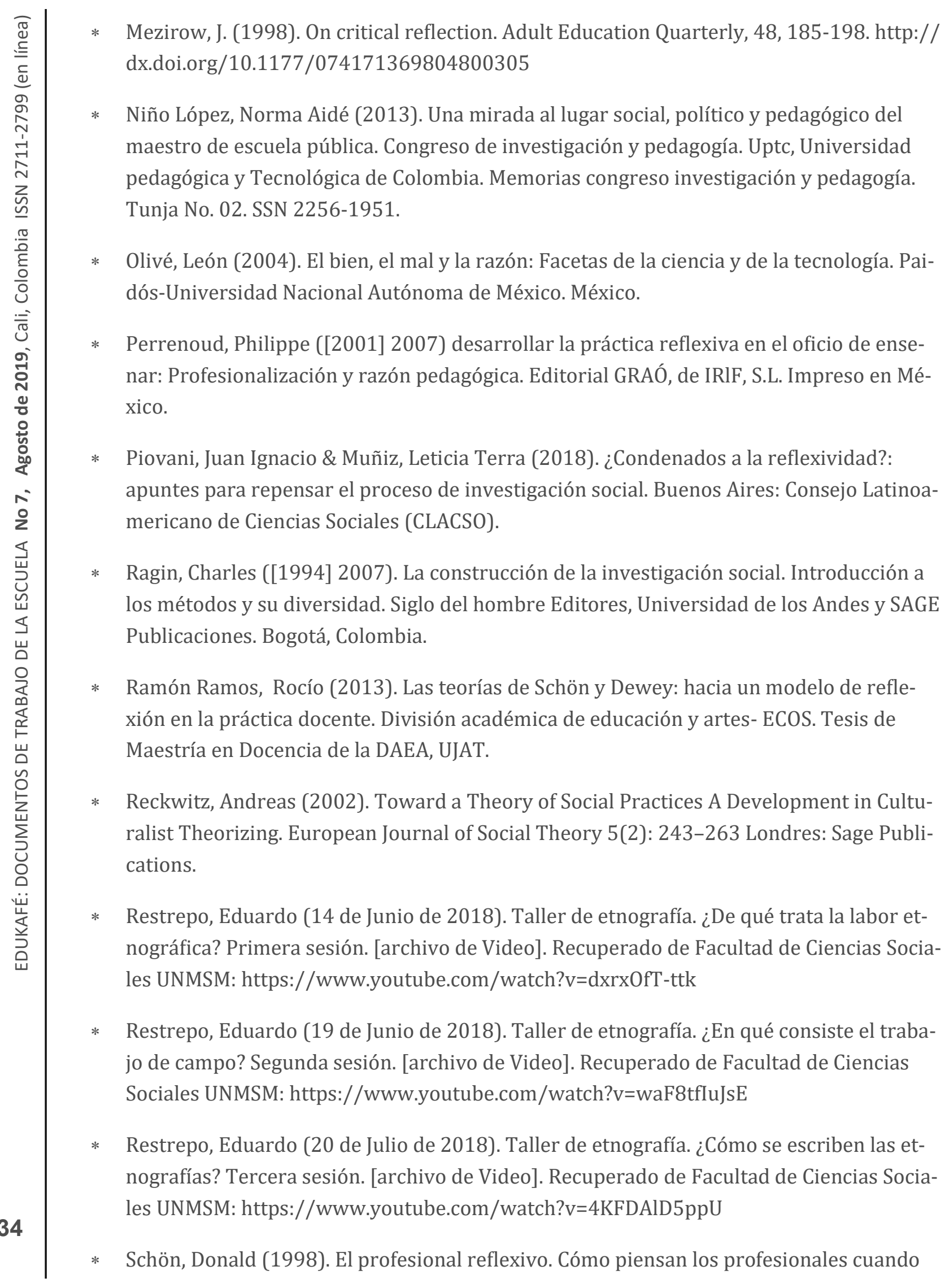


actúan. Paidós.

* Sperber, Dan (1991). Etnografía interpretativa y antropología teórica. Alteridades, vol. 1, núm. 1, -, 1991, pp. 111-128. Universidad Autónoma Metropolitana Unidad Iztapalapa. Distrito Federal, México.

* Tapella, Esteban \& Rodriguez-Bilella, Pablo (2014). Sistematización de experiencias: una metodología para evaluar intervenciones de desarrollo. Revista de Evaluación de Programas y Políticas Públicas, Núm. 3, pp.80-116.

* Touraine, Alain (1994). Crítica de la modernidad., Buenos Aires: Fondo de Cultura Económica.

* Touraine, Alain (1996). ¿Podemos vivir juntos? Buenos Aires: Fondo de Cultura Económica.

* Villena Fiengo, Sergio (2003). Walter Benjamín o la historia a contrapelo. En: Revista Ciencias Sociales Universidad de Costa Rica No 100, pág., 95-101. https:// www.revistacienciassociales.ucr.ac.cr/images/revistas/RCS100/08VILLENA.pdf

* Weber, Max ([1964] 2002). Economía y sociedad. Fondo de Cultura Económica, Impreso en España. 


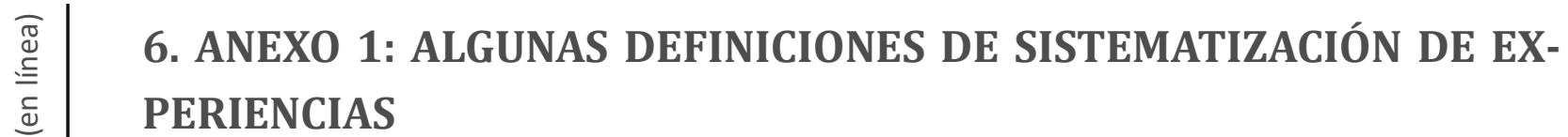

Sin pretender construir una lista exhaustiva, a continuación, se presenta un conjunto de definiciones de sistematización de experiencias que deja entrever lo polisémico del término, pues no hay una definición única y precisa.

Mejía, Marco Raúl (2010). La sistematización empodera y produce saber y conocimiento. Bogotá: ediciones desde abajo

$\Rightarrow$ La sistematización es ese saber sobre las prácticas y el proceso de investigación cualitativo, que es realizado por los grupos que llevan a cabo la práctica, existiendo múltiples entendimientos y concepciones de esa sistematización que nos sirven para reconocer distintas maneras de realizarla, de utilizar los instrumentos, y que han ido generando una producción de saber desde las prácticas que ha ido dialogando con el saber constituido y construyendo nuevos saberes, mostrando caminos e interpretaciones nuevas [pp. 18]

Junta de Andalucía, Manual para la introducción de la perspectiva de género y juventud al desarrollo rural.

$\Rightarrow$ La sistematización es aquella interpretación crítica de una o varias experiencias, que a partir de su ordenamiento y reconstrucción, descubre o explicita la lógica del proceso vivido, los factores que han intervenido en dicho proceso, cómo se han relacionado entre sí, y por qué lo han hecho de esa manera [tomado de Tapella \& Rodriguez (2014)].

Selener, D. (1996) A Participatory Systematization Workbook: Documenting,

$\Rightarrow$ En términos generales la sistematización es un proceso de reflexión participativa efectuado por los facilitadores y participantes de un proyecto (ONGs, agencias financieras, organizaciones beneficiarias, etcétera) sobre diferentes aspectos de un proyecto o programa, incluyendo sus procesos y resultados. Es una metodología que facilita la descripción concurrente, el análisis y documentación del proceso y los resultados de un proyecto de desarrollo de una manera participativa. [tomado de Tapella \& Rodriguez (2014)].

Fondo Mink’a de Chorlaví (2002).

$\Rightarrow$ La sistematización es el proceso de reconstrucción y análisis crítico de una experiencia de desarrollo, implementada con la participación activa y directa de aquellos actores involucrados en una experiencia, para generar lecciones y producir conocimientos que permitan mejorar la efectividad y eficiencia de esa y otras experiencia similares. [tomado de Tapella \& Rodriguez (2014)].

36

Jara, Oscar. (1998) ‘Para sistematizar experiencias’ ALFORJA. San José, Costa Rica. 
$\Rightarrow$ La sistematización es aquella interpretación crítica de una o varias experiencias que, a partir de su ordenamiento y reconstrucción, descubre o explicita la lógica del proceso vivido, los factores que han intervenido en dicho proceso, cómo se han relacionado entre sí, y por qué lo han hecho de ese modo [tomado de Tapella \& Rodriguez (2014)].

Morgan-T, ML y Quiroz, T. (1988) 'Acerca de la Sistematización', en 'La Sistematización de la Práctica: Cinco Experiencias con Sectores Populares'. Buenos Aires, Argentina: HUMANITAS-CELATS.

$\Rightarrow$ A través de la descripción, organización y análisis del desarrollo de una actividad, la sistematización apunta a extraer lecciones de la experiencia de una manera global en una pluralidad de áreas, tales como la teoría y metodología utilizada, el contexto institucional y sociohistórico, las relaciones entre el agente externo y los pobladores, y la descripción de los procesos de organización comunitaria y desarrollo, incluyendo un análisis de los factores que obstaculizaron y facilitaron el trabajo del grupo, y los resultados e impactos de la experiencia [tomado de Tapella \& Rodriguez (2014)].

Schouten, T. (2007) 'Process Documentation', in Learning Alliance Briefing No 6, IRC International Water and Sanitation Centre., Lodz, Poland, 1-5 July

$\Rightarrow$ La intervención en escenarios de desarrollo es un mundo complejo que merece ser comprendido desde la reflexión crítica. La sistematización es una metodología útil que nos permite comprender y aprender acerca de las diversas curvas, obstáculos y desvíos que supone el camino de un proyecto [tomado de Tapella \& Rodriguez (2014)].

\section{Grupo de Investigación en Recursos y Teorías para el Aprendizaje (IRTA)}

\author{
https://bit.ly/2NPBvrn
}

IRTA es el grupo de investigación de la Escuela de Ciencias de la Educación de la Universidad Icesi. Tiene como objetivos construir propuestas teórico metodológicas, para diversos campos del saber, que los docentes de las diferentes disciplinas puedan utilizar para alcanzar los objetivos de formación y aprendizaje propuestos en sus procesos de enseñanza y aprendizaje; definir modelos para validar y verificar la operacionalización de los conceptos y fundamentos del aprendizaje contenidos en el proyecto educativo de la Universidad; y, estructurar un conjunto de métodos, técnicas y actividades para guiar la aplicación de las tecnologías de información y comunicación (TIC) en procesos de aprendizaje. Desarrolla investigaciones en los campos educativo y pedagógico, así como investigaciones aplicadas e intervenciones que buscan incidir y transformar las realidades educativas.

\section{LÍNEAS DE INVESTIGACIÓN}

1. Didácticas, pedagogía y aprendizajes

2. Currículo y evaluación

3. TIC y educación

4. Entornos, gestión y políticas educativas

5. Experiencias de formación y transformación educativa: sujetos y lenguaje

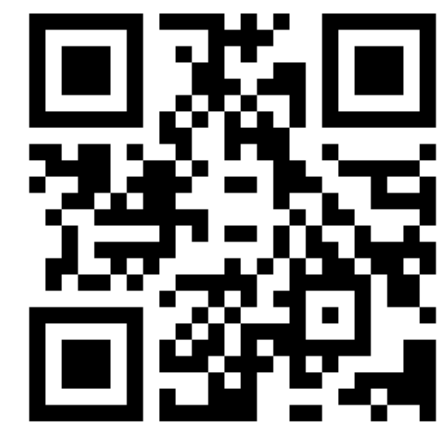


